\title{
Synthesis and Properties of Targeted Radioisotope Carriers Based on Poly(Acrylic Acid) Nanogels
}

\author{
Małgorzata Matusiak ${ }^{1}$, Beata P. Rurarz ${ }^{1}{ }^{\circledR}$, Sławomir Kadłubowski ${ }^{1}$, Marian Wolszczak ${ }^{1}$,

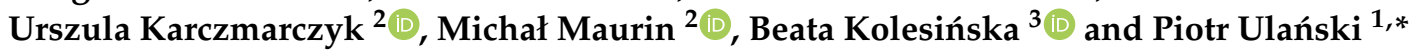 \\ 1 Institute of Applied Radiation Chemistry, Faculty of Chemistry, Lodz University of Technology, \\ Wróblewskiego 15, 93-590 Lodz, Poland; malgorzata.matusiak.1@p.lodz.pl (M.M.); \\ beata.rurarz@dokt.p.lodz.pl (B.P.R.); slawomir.kadlubowski@p.lodz.pl (S.K.); \\ marian.wolszczak@p.lodz.pl (M.W.) \\ 2 National Centre for Nuclear Research, Radioisotope Centre POLATOM, Andrzeja Sołtana 7, \\ 05-400 Otwock, Poland; urszula.karczmarczyk@polatom.pl (U.K.); michal.maurin@polatom.pl (M.M.) \\ 3 Institute of Organic Chemistry, Faculty of Chemistry, Lodz University of Technology, Żeromskiego 116, \\ 90-924 Lodz, Poland; beata.kolesinska@p.lodz.pl \\ * Correspondence: piotr.ulanski@p.lodz.pl; Tel.: +48-42-631-3184
}

\section{check for} updates

Citation: Matusiak, M.; Rurarz, B.P.; Kadłubowski, S.; Wolszczak, M.; Karczmarczyk, U.; Maurin, M.; Kolesińska, B.; Ulański, P. Synthesis and Properties of Targeted Radioisotope Carriers Based on Poly(Acrylic Acid) Nanogels Pharmaceutics 2021, 13, 1240. https://doi.org/10.3390/ pharmaceutics 13081240

Academic Editor: Leonard I. Wiebe

Received: 3 June 2021

Accepted: 6 August 2021

Published: 11 August 2021

Publisher's Note: MDPI stays neutral with regard to jurisdictional claims in published maps and institutional affiliations.

Copyright: (C) 2021 by the authors Licensee MDPI, Basel, Switzerland. This article is an open access article distributed under the terms and conditions of the Creative Commons Attribution (CC BY) license (https:// creativecommons.org/licenses/by/ $4.0 /)$.
Abstract: Radiation crosslinking was employed to obtain nanocarriers based on poly(acrylic acid)PAA - for targeted delivery of radioactive isotopes. These nanocarriers are internally crosslinked hydrophilic macromolecules-nanogels-bearing carboxylic groups to facilitate functionalization. PAA nanogels were conjugated with an engineered bombesin-derivative-oligopeptide combined with 1,4,7,10-tetraazacyclododecane-1,4,7,10-tetraacetate chelating moiety, aimed to provide selective radioligand transport. 4-(4,6-Dimethoxy-1,3,5-triazin-2-yl)-4-methylmorpholinium (DMTMM) toluene-4-sulfonate was used as the coupling agent. After tests on a model amine- $-\mathrm{p}$-toluidine-both commercial and home-synthesized DOTA-bombesin were successfully coupled to the nanogels and the obtained products were characterized. The radiolabeling efficiency of nanocarriers with ${ }^{177} \mathrm{Lu}$, was chromatographically tested. The results provide a proof of concept for the synthesis of radiation-synthesized nanogel-based radioisotope nanocarriers for theranostic applications.

Keywords: radiation chemistry; biomaterials; poly(acrylic acid); biomedical applications; nanocarriers; nanogels; DMTMM; conjugation; bombesin; DOTA; radioisotopes

\section{Introduction}

In recent years targeted nanotherapeutics have attracted significant attention. Many carriers as well as targeting ligands have been intensively explored to enable reaching tumor cells in tailored, precise way. A growing body of evidence supports the feasibility of this approach, and an increasing number of formulations is entering clinical trials [1-4]. Such formulations should be designed in a way that assures that following functionalities are introduced: therapeutic moiety-a delivery vehicle or protein, carrying the therapeutic cargo; targeting ligand-a specific probe, e.g., a small organic molecule, peptide, or antibody able to bind with specific components of the cell, facilitating transport of the construct into the target site $[5,6]$. The application of nanocarriers allows for the improvement of therapeutic agents' pharmacokinetics, alters hydrophobic drug solubility in water-based formulations, and alleviates their degradation and clearance by the reticuloendothelial system (RES) components.

One of the most interesting candidates for carriers in targeted nanotherapy are nanogels-spherical polymer networks of internally crosslinked macromolecules with high water content [7]. The open structure of such "frozen coils" is permeable for water molecules and low-molecular-weight solutes. This provides the opportunity for the transport of biologically active compounds in a fluid-like manner, while protecting them against 
decomposition and ameliorating the side effects of the treatment [8-11]. Nanogels have drawn significant attention also because of their exceptional biocompatibility, high stability, and relatively easy tuning of size, surface properties, softness, and degradability by altering the chemical composition [12,13]. The incorporation of particular functional groups in the crosslinked polymer structure can induce sensitivity of the particle to environmental factors (e.g., $\mathrm{pH}$, temperature, ionic strength, or light); hence, external stimuli may lead to the controlled release of therapeutic cargo transported by the construct [12,14]. Moreover, groups like $-\mathrm{OH},-\mathrm{COOH},-\mathrm{SH}$, or $-\mathrm{NH}_{2}$ enable convenient bioconjugation of targeting ligands [14-17].

There is a myriad of methods for nanogel preparation, in which physically or chemically crosslinked structures can be obtained $[18,19]$. Among them, radiation-induced synthesis is particularly attractive. It allows the crosslinking reaction to be carried out without adding harmful initiators or crosslinking agents, rendering the obtained nanoparticles suitable for biomedical applications. This method, exploited by our research group for more than 20 years, allows nanogels to be synthesized from various polymers [20-27]. Poly(acrylic acid) (PAA) is of particular importance. Linear and crosslinked PAA is a component of a number of approved drugs, including ocular drops. Its potential as a material for biomedical application is based on the presence of carboxylic groups: They provide good water solubility, responsiveness of the material to changing $\mathrm{pH}$, and an opportunity for convenient bioconjugation. Moreover, it was shown that the interaction of poly(acrylic acid) with lipid bilayers may destabilize those layers and make them more prone to leakage in a $\mathrm{pH}$-dependent manner. This phenomenon can play an important supporting role in the endosomal escape of the structures based on PAA [28-32]. Nanogels bearing carboxylate groups, synthesized by a similar procedure as the one used in this work, have been demonstrated to be promising nanocarriers for certain drugs [33], oligonucleotides [34], and siRNA [17]. Moreover, it has been shown that such nanogels are capable of bypassing the cell membranes and also crossing the blood-brain barrier while carrying a drug used in therapy for Alzheimer's disease [35,36].

Conjugation of targeting ligands or therapeutic agents to the carboxylic group-bearing nanocarriers is frequently used for nanotherapeutics synthesis [37-44]. It allows for the formation of both cleavable $\mathrm{pH}$-sensitive connections via ester bonds [45,46], as well as permanent stable amide linkage, which is particularly interesting in the case of biologically active molecules. Condensation of primary amines with nanoparticle carboxylic groups is most commonly performed using carbodiimide chemistry based on 1-ethyl3-(3-dimethylaminopropyl)carbodiimide (EDC) and N-hydroxysuccinimide (NHS)/Nhydroxysulfosuccinimide (sulfo-NHS) [47]. Yet, this field can still benefit from further investigation, as there are limited chemical groups that are able to specifically react with carboxylic acids [48]. Recently there has been some attention paid to the other class of coupling agents based on organic triazine derivatives. First, and one of the most popular of this class, is (4,6-dimethoxy-1,3,5-triazin-2-yl)-4-methyl-morpholinium (DMTMM) chloride, which was first reported in 1999 by Kunishiwa et al. [49] and since then it has been primarily used as an amide coupling agent in organic chemistry, particularly in peptide synthesis [50]. Since its first applications, some improvements have been proposed to DMTMM chemistry, mainly by the optimization of the tertiary amine and counterion of the compound [51,52].

Successful application of DMTMM in novel nanotherapeutics development is becoming prominent and an increasing number of nanocarriers is shown to be compatible with $\mathrm{N}$-triazinylammonium chemistry. Numerous works indicate the versatility of this approach, allowing for peptides to be coupled to various polymeric carriers, e.g., hyaluronic acid [44], PEG-based block copolymers linked to near-infrared dye IR-780 with photothermal and photodynamic properties [53], and poly-L-glutamic acid [54]. Conejos-Sánchez et al. [55] examined multiple conjugation chemistries for amide linkage formation and found DMTMM activation to be the most reproducible. They used two variants of the compound with various counterions $\left(\mathrm{Cl}^{-}\right.$and $\left.\mathrm{BF}_{4}{ }^{-}\right)$to attach doxycycline to their PGA drug carrier. More- 
over, they successfully incorporated the chelating 1,4,7,10-tetraazacyclododecane-1,4,7,10tetraacetate (DOTA) moiety in their polymer-drug conjugate for radioactive labeling with a positron-emitting ${ }^{68} \mathrm{Ga}$ radionuclide.

DOTA is a well-known chelate for lanthanide ions. The resulting chelated complexes have several applications in medicine, e.g., they are used as cancer treatment drugs or contrast agents. When considering the use of DOTA chelators in cancer diagnosis, they are commonly used as a chelating agent connected to monoclonal antibodies (e.g., Yttrium $\left({ }^{90} \mathrm{Y}\right)$ clivatuzumab tetraxetan [56], Yttrium $\left({ }^{90} \mathrm{Y}\right)$ tacatuzumab tetraxetan [57]), and small peptides that have an affinity for specific receptors (e.g., DOTATOC, DOTA-TATE [58], DOTA-biotin [59]). There is also a well-known application of DOTA in an MRI contrast agent under the name of gadoteric acid, in which $\mathrm{Gd}^{3+}$ is used with the DOTA complex [60].

The incorporation of radioactive components turned out to be a very attractive direction in targeted nanotherapeutics development, and functional nanoparticles labeled with radionuclides have been proposed as a new category of materials. They offer the possibility to exploit the already established principles of nuclear medicine. At the same time, they are also taking advantage of targeting methods as well as other therapeutic and diagnostic modalities elaborated to maximize the effects of treatment with nanomedicine [6]. This novel class of nanoparticulate formulations became a scope of a brand new field of medical science-radionanomedicine [61].

Numerous challenges are in the way of using targeted radionanotherapeutics in the clinic - they have to satisfy the requirements both for nanotherapeutics and radiopharmaceuticals. The final products must ensure high specific activity and sufficient radiostability, achieved by quick, efficient, and safe labeling, and excellent biocompatibility and biodistribution of the nanocarrier is essential. Despite the complex nature of the matter, many researchers are exploring radionanomedicine with promising results [62,63].

The objective of this paper is to present a novel approach to the development of nanoscale carriers based on poly(acrylic acid) nanogels for the targeted delivery of cancer diagnostic and therapeutic agents. The developed carriers are expected to be a common platform to deliver radionuclides for cancer diagnosis and therapy. A selective targeting ability was introduced to the construct by the use of a specially modified targeting ligand-bombesin derivative. The binding region of this peptide shows agonistic affinity to the gastrin-releasing peptide receptor (GRPR), abundantly expressed in many neoplastic conditions, such as breast, prostate, or pancreatic cancer. In this work, the DOTA-bombesin derivative is applied as a chelator for a wide range of radionuclides, e.g., lutetium-177, yttrium-90, and gallium-68, which, with high target specificity, can detect and treat cancer cells. Furthermore, in the future approach, DOTA chelators as an independent derivative can modify the surface of the nanoparticles to achieve a higher radiation dose by more efficient radiolabeling. As an alternative use, DOTA chelators may be labelled with Gd, commonly used in magnetic resonance as a contrast agent, or the surface can be modified by the attachment of fluorophores for optical imaging.

The developed nanocarrier platform allowed radiolabeled nanogels to be obtained, characterized by the radiochemical yield of $99.0 \pm 1.1 \%$ and specific activity of 0.77 [GB mg ${ }^{-1}$ ]. Thus, this preliminary study provides a proof-of-concept for the synthesis and functionalization of radiation-derived nanogels for theranostic applications. However, additional studies will be performed to optimize the nanogel radionuclide loading content and their specific activity.

\section{Materials and Methods}

\subsection{Materials}

The following chemicals were used for nanogel synthesis and analysis of the physicochemical properties: poly(acrylic acid) (PAA) of nominal weight-average molecular weight $4.5 \times 10^{5} \mathrm{Da}$ (Sigma-Aldrich, St. Louis, MO, USA), sodium hydroxide $(\mathrm{NaOH}$, pure PA, POCH SA), perchloric acid $\left(\mathrm{HClO}_{4}, 70 \%\right.$, Sigma-Aldrich), and sodium perchlorate $\left(\mathrm{NaClO}_{4} \cdot \mathrm{H}_{2} \mathrm{O}\right.$, Sigma-Aldrich). Solutions were prepared using TKA-Micropure filtered 
water and ULC/MS-grade water from Biosolve with high purity and high UV transmission. Argon (5.0, Ar $\geq 99.999 \%$, Linde Gaz Polska, Kraków, Poland) was used to saturate the solutions prior to irradiation.

The nanogels were modified using p-toluidine (Sigma-Aldrich) as a model compound, and with a 1,4,7,10-tetraazacyclododecane-1,4,7,10-tetraacetate (DOTA)-bombesin derivative, Lys1Lys3(DOTA)-bombesin 1-14 (BD) (Scheme 1), with the following sequence: LysGln-Lys(DOTA)-Leu-Gly-Asn-Gln-Trp-Ala-Val-Gly-His-Leu-Met-NH 2 (CS Bio Co. 95.75\% and synthesized by authors). 4-(4,6-dimethoxy-1,3,5-triazin-2-yl)-4-methylmorpholinium toluene-4-sulfonate $\left(\mathrm{DMT} / \mathrm{NMM} / \mathrm{TsO}^{-}\right.$) (synthesized by the Institute of Organic Chemistry, TUL) and acetonitrile for UPLC (POCH SA) were used as the coupling agent and solvent, respectively.

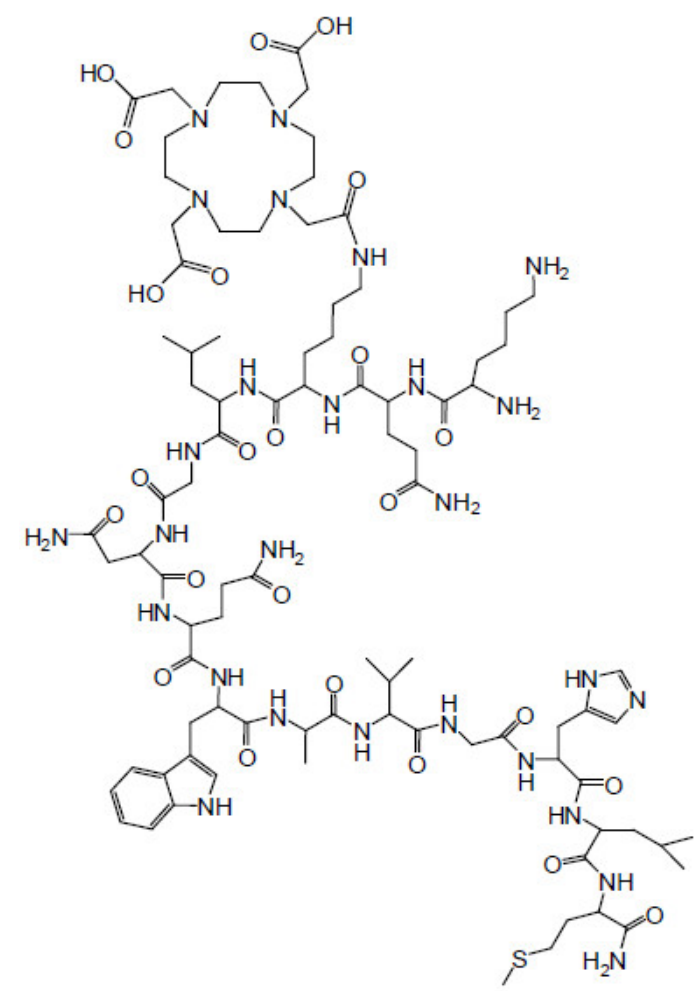

Scheme 1. Structure of Lys1Lys3(DOTA)-bombesin 1-14.

The step-by-step oligopeptide synthesis was performed using Rink amide resin (200-400 mesh, Sigma-Aldrich), 2-chlorotritylchloride resin (100-200 mesh, Novabiochem, Merck, Darmstadt, Germany), and protected amino acids (INTAVIS Bioanalytical Instruments AG): Fmoc-Met-OH, Fmoc-Leu-OH, Fmoc-His(Trt)-OH, Fmoc-Gly-OH, Fmoc-Val$\mathrm{OH}$, Fmoc-Ala-OH, Fmoc-Trp(Boc)-OH, Fmoc-Gln(Trt)-OH, Fmoc-Asn(Trt)-OH, FmocLys(Alloc)-OH, Fmoc-Lys(Boc)-OH, tri-tert-butyl 1,4,7,10-tetraazacyclododecane-1,4,7,10tetraacetate (DOTA-tri-t-Bu-ester, $\geq 95.0 \%$, Sigma-Aldrich), 4-methylmorpholine (NMM, ReagentPlus ${ }^{\circledR}, 99 \%$ ), N,N-dimethylformamide (DMF, pure, POCH S.A.), dichloromethane $\left(\mathrm{CH}_{2} \mathrm{Cl}_{2}, 99,8 \%\right.$ pure P.A.-basic, POCH S.A.), piperidine (ReagentPlus $\left.{ }^{\circledR}, 99 \%\right)$, methanol (MeOH, 99.8\% POCH S.A.), N,N-diisopropylethylamine (DIPEA, 99.5\%, Sigma-Aldrich), phenylsilane $\left(\mathrm{PhSiH}_{3}, 97 \%\right.$, Fluorochem), tetrakis(triphenylphosphine)palladium $(0)\left(\mathrm{Pd}\left(\mathrm{PPh}_{3}\right)_{4}\right.$, 99\%, Sigma-Aldrich), benzotriazole-1-yl-oxy-tris-(dimethylamino)-phosphonium hexafluorophosphate (BOP, $\leq 100 \%$ Novabiochem), Hexafluoroisopropanol (HFIP, 99\%, SigmaAldrich), trifluoroacetic acid (TFA, $\geq 99.0 \%$, Sigma-Aldrich), 1,2-ethanedithiol (EDT, $\geq 98.0 \%$, Sigma-Aldrich), and triethylsilane (TIS, 99\%, Sigma-Aldrich).

Sample dialysis was performed with cellulose membrane tubing (molecular weight cut-off 14.000, Sigma-Aldrich). 
The following chemicals were used for radiolabeling: $\mathrm{L}(+)$-ascorbic acid (PanReac AppliChem, cat.no. 141013.1211), sodium hydroxide 30\% solution ( $\mathrm{NaOH}, 99 \%$, Merck), diethylenetriaminepentaaceticacid (DTPA, Merck), and lutetium-177 (LutaPol) as lutetium chloride $\left[{ }^{177} \mathrm{Lu}\right] \mathrm{LuCl}_{3}$, carrier added, of SA (specific activity) higher than $555 \mathrm{MBq} \mathrm{mg}^{-1}$ $\mathrm{Lu}$ in $0.04 \mathrm{~N} \mathrm{HCl}$ in a volume of $0.010-2 \mathrm{~mL}$, produced at Radioisotope Centre POLATOM, Otwock, Poland.

\subsection{Radiation-Induced Synthesis of Nanogels}

Poly(acrylic acid) nanogels (NG) were synthesized as reported previously [24,26] (see also Section 3.1.). Briefly, a dilute aqueous solution of linear PAA in a monomer unit concentration of $22.5 \mathrm{mmol} \cdot \mathrm{dm}^{-3}(1.62 \mathrm{~g} / \mathrm{L})$ was prepared overnight by stirring at $50{ }^{\circ} \mathrm{C}$. Since the reaction has to be performed in acidic medium, the $\mathrm{pH}$ of the polymer solution was adjusted to 2.0 with perchloric acid, as an acid of relatively high resistance to ionizing radiation [64]. Finally, the solution was circulated in a closed-loop system and flowed through a quartz irradiation cell, and was Ar-saturated and irradiated by short pulses of fast electrons generated by an ELU-6 linear accelerator (Elektronika, Moscow, Russia). Irradiation parameters: pulse duration $2 \mu$ s, pulse frequency $0.5 \mathrm{~Hz}$, electron energy $6 \mathrm{MeV}$, absorbed dose of ionizing radiation per single pulse 0.9-1.1 kGy, as determined by alanine dosimeter (e-scan, Bruker, Billerica, MA, USA) [65]. After synthesis, the nanogel solutions were stored at $10{ }^{\circ} \mathrm{C}$. Directly before coupling they were filtered through $1.2,0.8$, and $0.45 \mu \mathrm{m}$ pore-size filters (Minisart NML, Sartorius, Göttingen, Germany).

\subsection{Nanogel Coupling with a Model Compound}

To examine the suitability of the chosen coupling method for the activation of the PAA nanogel carboxylic groups, first a test functionalization was performed with a simple amine model compound-p-toluidine. The coupling strategy employed was based on 4-(4,6dimethoxy-1,3,5-triazin-2-yl)-4-methylmorpholinium toluene-4-sulfonate (DMT/NMM/ $\mathrm{TsO}^{-}$, which will be called "ca" (coupling agent) for simplicity), the compound that was developed at the Institute of Organic Chemistry of Lodz University of Technology [52].

First, the proper amount of DMT/NMM $/ \mathrm{TsO}^{-}$(based on the molar ratios between the compounds in the final solution) was dissolved in ca. $5 \mathrm{~mL}$ of acetonitrile. Subsequently, $0.10 \mathrm{mmol}$ NMM $(11 \mu \mathrm{L})$ and $0.20 \mathrm{mmol} \mathrm{NG}(10 \mathrm{~mL})$ were added and the solution was stirred on ice. After 40 min of carboxylic group activation, an appropriate aliquot of $\mathrm{p}$ toluidine was added to the reaction. The solution was left for $12 \mathrm{~h}$ in an ice bath with no further ice supply to equilibrate the temperature to ambient conditions. After this time, the acetonitrile was removed from the solution using a rotary evaporator at $30{ }^{\circ} \mathrm{C}$ under vacuum. Finally, the solution was centrifuged (13 min, $9000 \mathrm{rpm}$ ) and the precipitate (unreacted substrates) was removed. According to the abovementioned procedure, four different reactions with varying molar ratios between carboxylate groups of PAA nanogels (NG), DMT/NMM/TsO- (ca), and p-toluidine molecules (T) were carried out as specified in Table 1 . The samples after coupling were stored at a temperature of $10^{\circ} \mathrm{C}$.

Table 1. Molar ratios between carboxylate groups of PAA nanogels (NG), DMT/NMM/TsO- (ca), and p-toluidine molecules (T).

\begin{tabular}{cccc}
\hline Sample & NG Carboxylate Groups & DMT/NMM/TsO $^{-}$ & p-Toluidine $^{\text {D }}$ \\
\hline $\mathrm{NG} / \mathrm{ca} / \mathrm{T} 1 / 1 / 1$ & 1 & 1 & 1 \\
$\mathrm{NG} / \mathrm{ca} / \mathrm{T} 2 / 1 / 2$ & 2 & 1 & 2 \\
$\mathrm{NG} / \mathrm{ca}$ T 10/1/10 & 10 & 1 & 10 \\
$\mathrm{NG} / \mathrm{ca} / \mathrm{T} 10 / 10 / 1$ & 10 & 10 & 1 \\
\hline
\end{tabular}

\subsection{In-House Synthesis of Custom Bombesin Derivative}

To prove the versatility of the chosen $N$-triazinylammonium sulfonate coupling strategy, synthesis of the DOTA-bombesin derivative was also attempted in our lab. The peptide was built from the Fmoc-protected amino acids using solid-phase peptide synthesis (SPPS) 
and 4-(4,6-dimethoxy-1,3,5-triazin-2-yl)-4-methylmorpholinium toluene-4-sulfonate as a condensing reagent. The stepwise synthetic procedure is described below.

\subsubsection{Rink Amide Resin Loading}

First, amino acid-Fmoc-protected methionine ( 3 equiv. rel. to the $0.40 \mathrm{mmol}$ loaded resin $=1.20 \mathrm{mmol}$ ), $\mathrm{DMT} / \mathrm{NMM} / \mathrm{TsO}^{-}$( 3 equiv. rel. to the resin $=1.20 \mathrm{mmol}$ ), and NMM ( 6 equiv. rel. to the resin $=2.40 \mathrm{mmol}$ ) were dissolved in DMF $(4 \mathrm{~mL})$. A total of $400 \mathrm{mg}$ of Rink amide resin (amine group load of $1.00 \mathrm{mmol} / \mathrm{g}$ ) was preswollen in $3 \mathrm{~mL}$ of $\mathrm{CH}_{2} \mathrm{Cl}_{2}$ for $1 \mathrm{~h}$, and after this time the solution containing the protected amino acid was added and the resin was shaken for $24 \mathrm{~h}$. Finally, the resin was washed with $4 \mathrm{~mL} \mathrm{DMF}(3 \times)$ and $4 \mathrm{~mL}$ $\mathrm{CH}_{2} \mathrm{Cl}_{2}(3 \times)$. A Kaiser test [66] confirmed complete resin loading.

\subsubsection{Deprotection}

The Fmoc protecting group was removed by treatment with a $4 \mathrm{~mL}$ solution of $25 \%$ piperidine in DMF $(2 \times 15 \mathrm{~min})$. After deprotection, the resin was washed with $4 \mathrm{~mL}$ of $\operatorname{DMF}(3 \times)$ and $4 \mathrm{~mL}$ of $\mathrm{CH}_{2} \mathrm{Cl}_{2}(3 \times)$.

\subsubsection{Standard Coupling Procedure}

Protected amino acid ( 3 equiv. rel. to the resin $=1.20 \mathrm{mmol}$ ), $\mathrm{DMT} / \mathrm{NMM} / \mathrm{TsO}^{-}$ ( 3 equiv. rel. to the resin $=1.20 \mathrm{mmol}$ ), and NMM ( 6 equiv. rel. to the resin $=2.40 \mathrm{mmol}$ approx. $300 \mu \mathrm{L})$ were dissolved in DMF $(4 \mathrm{~mL})$ and added to the resin. The resin was shaken for $24 \mathrm{~h}$. The progress of the reaction was monitored by the Kaiser test [66].

The following amino acids were coupled in a growing peptide chain by stepwise addition: Fmoc-Met-OH, Fmoc-Leu-OH, Fmoc-His(Trt)-OH, Fmoc-Gly-OH, Fmoc-Val-OH, Fmoc-Ala-OH, Fmoc-Trp(Boc)-OH, Fmoc-Gln(Trt)-OH, Fmoc-Asn(Trt)-OH, Fmoc-Gly-OH, and Fmoc-Leu-OH. The last seven amino acids were coupled using a LibertyBlue device (CEM Company, Matthews, NC, USA) that generates microwaves, accelerating the coupling process. The resin was dried after the coupling procedure.

\subsubsection{2-Chlorotrityl Chloride Resin Loading}

Protected amino acid-Fmoc-Lys(Alloc)-OH ( 3 equiv. rel. to the resin $=1.11 \mathrm{mmol}$ ) and DIPEA (6 equiv. $=2.22 \mathrm{mmol}$ approx. $400 \mu \mathrm{L})$ were dissolved in $\mathrm{CH}_{2} \mathrm{Cl}_{2}(10 \mathrm{~mL}$ per $1 \mathrm{~g}$ of the resin). A total of $300 \mathrm{mg}$ of 2-chlorotritylchloride resin (load carboxylic groups $1.23 \mathrm{mmol} / \mathrm{g}$ ) was preswollen in $3 \mathrm{~mL} \mathrm{CH}_{2} \mathrm{Cl}_{2}$ for $1 \mathrm{~h}$. After this time, the solution containing the protected amino acid was added and the resin was shaken for $2 \mathrm{~h}$. Finally, the resin was washed with $\mathrm{CH}_{2} \mathrm{Cl}_{2} / \mathrm{MeOH} / \mathrm{DIPEA}(17: 2: 1,20 \mathrm{~mL})$, then $4 \mathrm{~mL} \mathrm{DMF}(2 \times)$ and $4 \mathrm{~mL} \mathrm{CH}_{2} \mathrm{Cl}_{2}(3 \times)$.

\subsubsection{Deprotection}

To remove the Alloc protecting group of the lysine, $\mathrm{PhSiH}_{3}$ (24 equiv. rel. to the resin $=4.82 \mathrm{mmol}$ ) in $2 \mathrm{~mL}$ of $\mathrm{CH}_{2} \mathrm{Cl}_{2}$ in an atmosphere of inert gas (nitrogen) was added. Subsequently, after two minutes, 0.25 equiv. rel. to the resin $=0.05 \mathrm{mmol} \mathrm{Pd}\left(\mathrm{PPh}_{3}\right)_{4}$ in $6 \mathrm{~mL}$ of $\mathrm{CH}_{2} \mathrm{Cl}_{2}$ was added and the resin was shaken for $40 \mathrm{~min}$. As a last step, the resin was washed with $3 \mathrm{~mL} \mathrm{CH}_{2} \mathrm{Cl}_{2}(3 \times), 3 \mathrm{~mL} \mathrm{DMF}(3 \times)$, and $3 \mathrm{~mL} \mathrm{CH}_{2} \mathrm{Cl}_{2}(4 \times)$. The progress of the reaction was monitored by the Kaiser test [66].

2.4.6. Coupling of Tri-tert-butyl 1,4,7,10-tetraazacyclododecane-1,4,7,10-tetraacetate to Unprotected Lysine

DOTA-tri-t-Bu-ester (1.70 equiv. rel. to the resin $=0.35 \mathrm{mmol}), \mathrm{DMT} / \mathrm{NMM} / \mathrm{TsO}^{-}$ (1.70 equiv. rel. to the resin $=0.35 \mathrm{mmol}$ ), and NMM (4 equiv. rel. to the resin $=0.80 \mathrm{mmol}$ ) were dissolved in $\mathrm{CH}_{2} \mathrm{Cl}_{2} / \mathrm{DMF}(1: 1,6 \mathrm{~mL})$, added to the resin, and shaken for $12 \mathrm{~h}$. Then, the solution was removed and the resin was washed with $\mathrm{CH}_{2} \mathrm{Cl}_{2}$. The procedure, with the addition of DOTA-tri-t-Bu-ester, was repeated. The resin was again shaken in the mixture for $12 \mathrm{~h}$. The resin grains remained purple after the Kaiser test, so coupling was repeated 
again, but with a different coupling agent-BOP. DOTA-tri-t-Bu-ester (1.7 equiv. rel. to the resin $=0.349 \mathrm{mmol}$ ), BOP (1.7 equiv. rel. to the resin $=0.349 \mathrm{mmol}$ ), and NMM (over 4 equiv. rel. to the resin, exactly $0.9 \mathrm{mmol}$ ) were dissolved in $\mathrm{CH}_{2} \mathrm{Cl}_{2} / \mathrm{DMF}(1: 1,4 \mathrm{~mL})$ and added to the resin. The resin was shaken for $24 \mathrm{~h}$.

\subsubsection{Cleavage from the 2-chlorotritylchloride Resin}

Fmoc-Lys(DOTA-tri-t-Bu-ester)-OH was cleaved from the resin using HFIP/DCM (1:1, $20 \mathrm{~mL})$. Cleavage was carried out for $3.5 \mathrm{~h}$, then the resin was filtered off and the filtrate was evaporated under a nitrogen flow. The resulting precipitate was dissolved in deionized water/acetonitrile $(1: 1,6 \mathrm{~mL})$ and then frozen in liquid nitrogen and lyophilized.

\subsubsection{Coupling of Fmoc-Lys(DOTA-tri-t-Bu-ester)-OH to Peptide on Rink Amide Resin}

Fmoc-Lys(DOTA-tri-t-Bu-ester)-OH was coupled using the LibertyBlue device. The Rink amide resin was preswollen in $3 \mathrm{~mL} \mathrm{CH}_{2} \mathrm{Cl}_{2}$ for $1 \mathrm{~h}$. A solution with a concentration of $0.50 \mathrm{~mol} \cdot \mathrm{dm}^{-3}$ of DMT/NMM/TsO ${ }^{-}$in DMF and $2.00 \mathrm{~mol} \cdot \mathrm{dm}^{-3}$ solutions of NMM in DMF were prepared. Initially, from the last amino acid on the Rink amide resin-leucinethe Fmoc group was removed by treatment with a solution of 25\% piperidine in DMF. Then, $\mathrm{DMT} / \mathrm{NMM} / \mathrm{TsO}^{-}$solution was added to the peptide, as well as Fmoc-Lys(DOTA-tri-tBu-ester)-OH solution in DMF and NMM solution. At the end of the coupling, the resin was washed with DMF and then dried.

\subsubsection{Coupling of Fmoc-Gln(Trt)-OH and Fmoc-Lys(Boc)-OH}

The last two amino acids were coupled using the LibertyBlue device. The Rink amide resin was preswollen in $\mathrm{CH}_{2} \mathrm{Cl}_{2}$ for $1 \mathrm{~h}$. A total of $0.50 \mathrm{~mol} \cdot \mathrm{dm}^{-3}$ solution of $\mathrm{DMT} / \mathrm{NMM} / \mathrm{TsO}^{-}$in DMF and $2.00 \mathrm{~mol} \cdot \mathrm{dm}^{-3}$ solution of NMM in DMF was prepared. First, from the last amino acid on the Rink amide resin-lysine- the Fmoc group was removed by treatment with a solution of $25 \%$ piperidine in DMF. Then, $\mathrm{DMT} / \mathrm{NMM} / \mathrm{TsO}^{-}$solution was added to the peptide and Fmoc-Gln(Trt)-OH solution in DMF $\left(0.20 \mathrm{~mol} \cdot \mathrm{dm}^{-3}\right)$ and NMM solution. Then, the resin was washed with DMF and deprotection and coupling was repeated for Fmoc-Lys(Boc)-OH. The resin was washed with DMF and then dried.

\subsubsection{Cleavage from the Rink Amide Resin}

The peptides were cleaved from the resin using TFA $/ \mathrm{H}_{2} \mathrm{O} /$ EDT /TIS $(94 \%, 2.5 \%, 2.5 \%$, $1 \%, 5 \mathrm{~mL}$ ) solution. Cleavage was carried out for $4 \mathrm{~h}$, then the resin was filtered off and the filtrate was evaporated under a nitrogen flow. The resulting precipitate was dissolved in deionized water/acetonitrile $(1: 1,6 \mathrm{~mL})$ and then frozen in liquid nitrogen and lyophilized.

\subsubsection{Synthesis of Bombesin Derivative without DOTA}

As a reference material, a DOTA-free bombesin derivative was synthesized in a process similar to the abovementioned procedure. Fmoc-protected amino acids were coupled with $\mathrm{DMT} / \mathrm{NMM} / \mathrm{TsO}^{-}$and $\mathrm{NMM}$ on Rink amide resin. The protecting groups were removed by treatment with a solution of $4 \mathrm{~mL} 25 \%$ piperidine in DMF $(2 \times 15 \mathrm{~min})$, and after deprotection, the resin was washed with $3 \mathrm{~mL} \mathrm{DMF}(3 \times)$ and $3 \mathrm{~mL} \mathrm{CH}_{2} \mathrm{Cl}_{2}(3 \times)$.

\subsection{Nanogel Coupling with Bombesin Derivative}

The method developed by Kamiński and Kolesińska, described above for the model compound, was repeated for two types of bombesin derivatives (bombesin derivative without DOTA-in-house synthesized; DOTA-bombesin derivative, both in-house synthesized and later supplied externally by CS Bio Co.). DMT $/ \mathrm{NMM} / \mathrm{TsO}^{-}$was dissolved in ca. $5 \mathrm{~cm}^{3}$ acetonitrile and then $11 \mu \mathrm{L}$ of NMM $(0.10 \mathrm{mmol})$ and $10 \mathrm{~mL}$ of PAA nanogel solution $(0.20 \mathrm{mmol})$ were added. The molar ratio of the coupling agent to PAA nanogel carboxylic groups was 1:1 for the activation of all carboxylic groups. The samples after completed coupling were stored at $10^{\circ} \mathrm{C}$. Aliquots of both nanocarriers and raw nanogels were freeze-dried, (e.g., for radiolabeling experiments) and stored at $-20^{\circ} \mathrm{C}$. 
Coupling was performed with three different molar ratios of carboxylic groups of PAA nanogel to bombesin derivative, as described in detail in Table 2.

Table 2. Nanocarriers obtained from coupling PAA nanogels and bombesin derivatives.

\begin{tabular}{|c|c|c|c|}
\hline \multirow[b]{2}{*}{ Name of the Sample } & \multicolumn{2}{|c|}{ Molar Ratio } & \multirow{2}{*}{$\begin{array}{c}\text { Source and Type } \\
\text { of Bombesin Derivative }\end{array}$} \\
\hline & $\begin{array}{c}\text { Carboxylate Groups } \\
\text { of PAA Nanogel }\end{array}$ & $\begin{array}{c}\text { DOTA-Bombesin } \\
\text { Derivative }\end{array}$ & \\
\hline NGBD100H & 100 & 1 & $\begin{array}{l}\text { in-house synthesized, } \\
\text { with DOTA }\end{array}$ \\
\hline NGB100H & 100 & 1 & $\begin{array}{l}\text { in-house synthesized, } \\
\text { without DOTA }\end{array}$ \\
\hline NGBD100E & 100 & 1 & $\begin{array}{c}\text { supplied by external company, } \\
\text { with DOTA }\end{array}$ \\
\hline NGBD500E & 500 & 1 & $\begin{array}{c}\text { supplied by external company, } \\
\text { with DOTA }\end{array}$ \\
\hline NGBD1000E & 1000 & 1 & $\begin{array}{c}\text { supplied by external company, } \\
\text { with DOTA }\end{array}$ \\
\hline
\end{tabular}

Abbreviations: NGBD—nanogels conjugated with BD; NGB-nanogels conjugated with bombesin derivative 100/500/1000 - molar ratio of carboxylic groups to peptide; H-in-house synthesized peptide; E-externally supplied peptide.

\subsection{Purification of Nanogels Coupled with Model Compound/Oligopeptide}

Low-molecular-weight compounds formed during the coupling process (such as $2-$ hydroxy-4,6-dimethoxy-1,3,5-triazine and $N$-methylmorpholine p-toluenesulfonate), as well as unreacted reagents, were removed by dialysis in cellulose membrane tubing (molecular weight cut-off 14.000, Sigma-Aldrich) against a 30-fold excess of deionized water at room temperature. The purification process was controlled by absorbance measurements. Wherever the properties of coupled nanogels were compared to the raw nanoparticles, solutions of the latter were subjected to the same dialysis procedure before measurements.

\subsection{Characterization of Nanogels}

\subsubsection{Static Light-Scattering Measurements (SLS)}

The weight-average molecular weight and radius of gyration of linear PAA and PAA nanogels were determined by static multiangle laser light-scattering measurements using a BI-200SM goniometer (Brookhaven Instruments Corporation, Holtsville, NY, USA) with an Innova 90C Ar ion laser $(\lambda=514.5 \mathrm{~nm})$ at $25.0 \pm 0.1^{\circ} \mathrm{C}$, in an aqueous solution of $0.5 \mathrm{~mol} \cdot \mathrm{dm}^{-3} \mathrm{NaClO}_{4}, \mathrm{pH} 10(\mathrm{NaOH})$. This solvent ensured a compact conformation of PAA macromolecules required for the light-scattering measurements. The Zimm algorithm was used to analyze the SLS data, assuming the refractive index increment $\mathrm{d} n / \mathrm{d} c=0.30 \mathrm{~cm}^{3} \mathrm{~g}^{-1}$ [67]. Linear PAA and PAA nanogel solutions were filtered through a $0.45 \mu \mathrm{m}$-pore-size filter (Minisart NML, Sartorius) before measurement, and the solvent was filtered through a $0.2 \mu \mathrm{m}$-pore-size filter (Minisart NML, Sartorius).

\subsubsection{Dynamic Light-Scattering Measurements (DLS)}

To supplement the SLS data, the hydrodynamic radii of linear PAA and PAA nanogels in an aqueous solution of $0.5 \mathrm{~mol} \cdot \mathrm{dm}^{-3} \mathrm{NaClO}_{4}, \mathrm{pH} 10(\mathrm{NaOH})$, were measured using ZetaSizer Nano ZS (Malvern Instruments Ltd., Malvern, Worcestershire, United Kingdom) equipped with a $633 \mathrm{~nm}$ laser $\left(25.0 \pm 0.1^{\circ} \mathrm{C}\right)$. The purified nanogels, both raw and coupled with model compound/oligopeptide, were measured with the same device at neutral $\mathrm{pH}$ at $25.0 \pm 0.1^{\circ} \mathrm{C}$.

\subsubsection{FTIR Infrared Spectroscopy}

FTIR spectra of PAA nanogels, both before after coupling with the model compound or oligopeptide, were recorded in the transmission mode using a Nicolet Avatar 330 FTIR spectrophotometer (Thermo Nicolet Corporation, Madison, WI, USA) in the range of 400 to $4000 \mathrm{~cm}^{-1}$. Before measurement, the samples were freeze-dried, then mixed with $\mathrm{KBr}$ in a 1:100 $w / w$ ratio and formed into pellets. 


\subsubsection{UV-Vis Spectroscopy}

UV-Vis spectra were recorded to determine the efficiency of the product purification by dialysis. This method was also used to track the coupling of the model compound and oligopeptide to the nanogels. UV-Vis measurements in quartz cells of a $1 \mathrm{~cm}$ optical path were performed against water in the wavelength range of 190-900 $\mathrm{nm}$ using a Lambda 40 double-beam spectrophotometer (Perkin-Elmer, Waltham, MA, USA).

\subsubsection{Fluorescence Spectroscopy}

Emission spectra of raw PAA nanogels, bombesin-DOTA derivative, and PAA nanocarriers coupled with bombesin-DOTA derivative were collected using an Aminco-Bowman Series 2 spectrofluorometer (Spectronic Unicam, Rochester, NY, USA) equipped with a xenon lamp and a red-sensitive photomultiplier (Hamamatsu R928). The excitation wavelength was $280 \mathrm{~nm}$ for the excitation of tryptophan present in the oligopeptide structure. The excitation and emission slits were set to 4.0 and $2.0 \mathrm{~nm}$, respectively. The fluorescence measurements were performed in quartz cells with a $1 \mathrm{~cm}$ optical path.

\subsection{6. ${ }^{1} \mathrm{H}$ NMR Nuclear Magnetic Resonance Spectroscopy}

${ }^{1} \mathrm{H}$ NMR spectra were recorded for the nanogels before and after coupling with the model compound/oligopeptide. The freeze-dried samples were dissolved in deuterated water. The measurements were performed using a Bruker Avance II $700 \mathrm{MHz}$ UltraShield Plus NMR spectrometer (Bruker, Billerica, MA, USA).

\subsection{Radiolabeling of DOTA-Bombesin Derivative and Quality Control}

The samples of PAA nanogels coupled with DOTA-bombesin derivative were labeled with $\left[{ }^{177} \mathrm{Lu}\right] \mathrm{LuCl}_{3}(0.2-9.8 \mathrm{GBq})$. Each of the $1 \mathrm{mg}$ lyophilized NGBD samples was dissolved in $1 \mathrm{~mL}$ of water for HPLC (high-performance liquid chromatography). Next, $0.5 \mathrm{~mL}$ of NGBD was mixed with $0.2 \mathrm{~mL}$ of ascorbic acid sodium salt solution of $\mathrm{pH}=4.5-5.0$ and 2-100 $\mu \mathrm{L}$ of radionuclide were added. The sample was incubated at $95 \pm 5^{\circ} \mathrm{C}$ for $15 \mathrm{~min}$.

The final formulation's radiochemical yield (RCY) was determined by thin-layer chromatography on glass-fiber silica gel-coated plates (ITLC SG) with $0.2 \mathrm{M}$ potassium chloride $\mathrm{pH}=2.0-2.5$ as a mobile phase to differentiate between the free radionuclide and radiolabeled PAA nanogels. The radiolabeling yield was evaluated in a competitor's presence (10 mM DTPA) in excess, reacting with the unbound radionuclide.

\section{Results and Discussion}

\subsection{Radiation-Induced Synthesis of Nanogels}

Radiation-induced nanogel synthesis seems to be a convenient tool for obtaining carriers for oligopeptides, radioactive substances, or genes. This process is carried out without potentially harmful compounds, like catalysts, initiators, etc., which are vital in chemical synthesis. The mechanism of radiation-induced nanogel synthesis from dilute aqueous polymer solutions is well known [21,23-25,68-72]; ionizing radiation (e.g., $\gamma$-rays or electron beam) is absorbed by water and as a result, short-lived reactive species as hydroxyl radicals, hydrated electrons, and hydrogen atoms are formed. To maximize the yield of these radicals and avoid the formation of peroxyl radicals and subsequent polymer degradation, the solutions are saturated with argon or nitrous oxide $[64,67,73,74]$. The next step in the deoxygenated solution is hydrogen atom abstraction from macromolecules by - $\mathrm{OH}$ and $\mathrm{H} \bullet$, resulting in the formation of radicals on polymer chains. These radicals recombine with each other inside the polymeric coil, leading to intramolecular crosslinking and the formation of nanogels. PAA is a weak polyelectrolyte, so for nanogel synthesis, the appropriate $\mathrm{pH}$ is required where the chains attain coiled conformation and their segments do not repel each other. In a strongly acidic environment, below $\mathrm{pH}$ 2, PAA chains form hydrogen bonds and aggregate. At $\mathrm{pH}$, which is used during synthesis, carboxylic groups are protonated and there is less than $1 \%$ of charged units; therefore, the polymer behaves nearly like a neutral chain [75]. In more alkaline and neutral $\mathrm{pH}$, above the $\mathrm{pKa}$ 
of ca. 6.0-6.2 [76] the dominant reaction during the irradiation of PAA solutions is chain scission due to Coulombic forces between groups with the same electrostatic negative charge $\mathrm{COO}^{-}$, which keep the chain segments apart and thus prevent crosslinking. In the conditions exploited in this procedure, the predominant reaction was intramolecular crosslinking, which led to nanogel synthesis.

In this paper, PAA nanogels were synthesized by the above-described method [26], with the aim of their subsequent modification by conjugation, first by a simple model compound and finally by the oligopeptide-bombesin. This section briefly describes the synthesis and physical properties of PAA nanogels before coupling. The weight-average molecular weight $\left(M_{w}\right)$ and dimensions of the radius of gyration $\left(R_{g}\right)$ and hydrodynamic radius $\left(R_{h}\right)$, as well as the density of the polymer coil $\left(\rho_{\text {coil }}\right)$, are shown in Table 3 for two $22.5 \mathrm{~mol} \cdot \mathrm{dm}^{-3}$ solutions that were irradiated during two separate accelerator sessions, yielding two batches of nanogels. As a reference, the results obtained for the pristine linear polymer are also shown in the table. It should be noted that these parameters were measured under specific conditions, namely, in an aqueous solution of $0.5 \mathrm{~mol} \cdot \mathrm{dm}^{-3}$ $\mathrm{NaClO}_{4}, \mathrm{pH}$ 10. This solvent ensured a compact conformation of PAA macromolecules required for the light-scattering measurements.

Table 3. Molecular parameters: weight-average molecular weight $\left(M_{w}\right)$, radius of gyration $\left(R_{g}\right)$, hydrodynamic radius $\left(R_{h}\right)$, and density of polymer coil $\left(\rho_{\text {coil }}\right)$ of non-irradiated and irradiated PAA solutions. All these parameters were measured in an aqueous solution of $0.5 \mathrm{~mol} \cdot \mathrm{dm}^{-3} \mathrm{NaClO}_{4}$, $\mathrm{pH} 10$.

\begin{tabular}{ccccc}
\hline Sample & $\begin{array}{c}\boldsymbol{M}_{\boldsymbol{w}} \\
{\left[\mathbf{D a}=\mathbf{g} \cdot \mathbf{m o l}^{-\mathbf{1}}\right]}\end{array}$ & $\begin{array}{c}\boldsymbol{R}_{\boldsymbol{g}} \\
{[\mathbf{n m}]}\end{array}$ & $\begin{array}{c}\boldsymbol{R}_{\boldsymbol{h}} \\
{[\mathbf{n m}]}\end{array}$ & $\begin{array}{c}\boldsymbol{\rho}_{\text {coil }} \\
{[\mathbf{g} \cdot \mathbf{m o l}}\end{array}$ \\
\hline $\begin{array}{c}\text { Non-irradiated polymer } \\
\mathbf{n m}\end{array}$ & $(8.87 \pm 1.55) \times 10^{-3}$ & $115 \pm 17$ & $42 \pm 3$ & $0.14 \pm 0.04$ \\
$\begin{array}{c}\text { Nanogels irradiated at 5.3 kGy } \\
\text { (NG_I) }\end{array}$ & $(1.26 \pm 0.09) \times 10^{6}$ & $94 \pm 5$ & $45 \pm 4$ & $0.36 \pm 0.07$ \\
$\begin{array}{c}\text { Nanogels irradiated at 5.4 kGy } \\
\text { Nanogels irradiated at 5.4 kGy } \\
\text { and re-filtered (NG_II) }\end{array}$ & $(1.13 \pm 0.11) \times 10^{6}$ & $86 \pm 22$ & $35 \pm 1$ & $0.43 \pm 0.31$ \\
\hline
\end{tabular}

The weight-average molecular weight of the pristine polymer in the solution $(\mathrm{pH}=10$; $0.5 \mathrm{~mol} \cdot \mathrm{dm}^{-3} \mathrm{NaClO}_{4}$ ) was found to be $8.87 \times 10^{5} \mathrm{Da}$, with radius of gyration of $115 \mathrm{~nm}$ and a hydrodynamic radius of $42 \mathrm{~nm}$. Two batches of nanogels were synthesized by pulse-irradiating deoxygenated aqueous solutions of PAA at $\mathrm{pH} 2$ with a dose of ca. $5 \mathrm{kGy}$. The nanogels from the first batch, marked as NG_I (dose $5.3 \mathrm{kGy}$, final $M_{w}=(1.26 \pm 0.09) \times 10^{6} \mathrm{Da}, R_{g}=94 \pm 5 \mathrm{~nm}$, and $\left.R_{h}=45 \pm 4 \mathrm{~nm}\right)$, were used, without further filtration, for coupling with the model compound and DOTA-bombesin derivative supplied by an external company. The nanogels of the second batch NG_II (dose $5.3 \mathrm{kGy}$, final $M_{w}=(1.13 \pm 0.11) \times 10^{6} \mathrm{Da}, R_{g}=86 \pm 22 \mathrm{~nm}$, and $\left.R_{h}=35 \pm 0.8 \mathrm{~nm}\right)$, prior to further coupling steps, were filtered and the parameters changed to $M_{w}=(3.83 \pm 0.3) \times 10^{5} \mathrm{Da}$, $R_{g}=41 \pm 2 \mathrm{~nm}$, and $R_{h}=30 \pm 4 \mathrm{~nm}$. These nanogels were used for coupling tests with DOTA-bombesin derivative and bombesin derivative without DOTA, which were synthesized in the authors' laboratory. The absorbed dose of ca. $5 \mathrm{kGy}$ was chosen to induce sufficient internal crosslink density and stability of the so-formed structures. It was found that they were colloidally stable, both in water and biologically relevant solvents such as PBS or cell culture media (RMPI1640). Moreover, they could be also safely freeze-dried or stored for at least two months (data not shown). The density of the polymer coil of NG_I and NG_II was much higher than the original coils of the linear polymer. This result confirms that intramolecular crosslinking plays a dominant role during radiation synthesis, and as a result, more densely packed polymer coils are obtained; this phenomenon is characteristic for nanogels as internally crosslinked macromolecules [77]. To further prove this, the hydrodynamic radius was also measured at various $\mathrm{pH}$ and ion strength conditions ( $\mathrm{pH} 2$ vs. $\mathrm{pH} 10$ vs. aqueous solution of $0.5 \mathrm{~mol} \cdot \mathrm{dm}^{-3} \mathrm{NaClO}_{4}, \mathrm{pH} \mathrm{10}$ ) (Figure 1). It 
can be seen that in contrast to the non-irradiated linear polymer, the irradiated samples retained the compact conformation and small size in the changing environment.

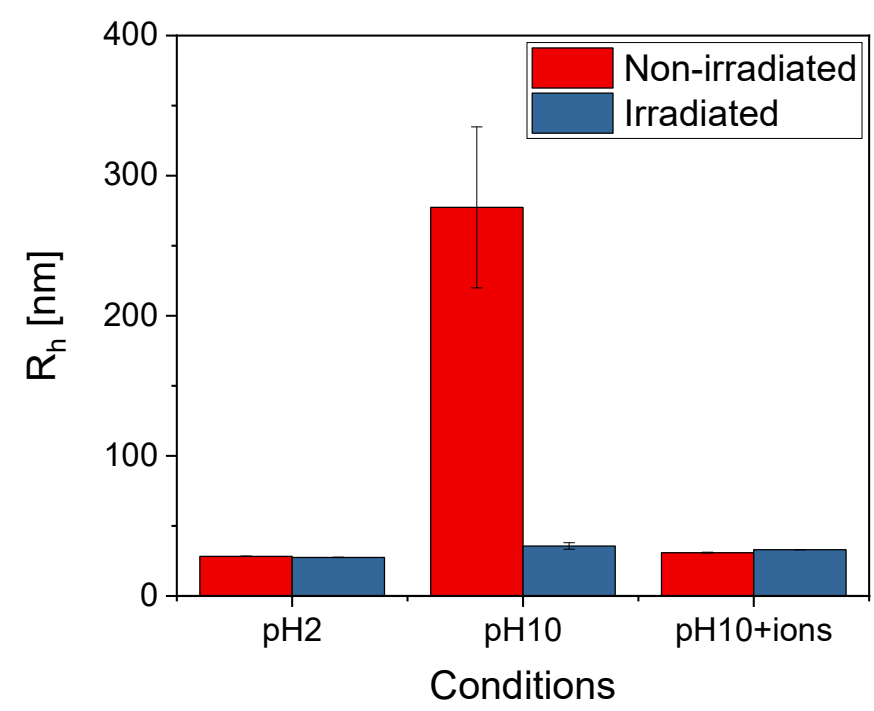

Figure 1. Hydrodynamic radii of PAA nanogels in aqueous solution at various conditions. $\mathrm{pH} 10+\mathrm{ions}$ indicates aqueous solution containing $0.5 \mathrm{~mol} \cdot \mathrm{dm}^{-3} \mathrm{NaClO}_{4}, \mathrm{pH} 10$.

\subsection{Coupling PAA Nanogels with a Simple Amine as Model Compound for Oligopeptide}

As a model compound for the oligopeptide, a simple aromatic amine-p-toluidine was used. PAA nanogels were successfully conjugated with p-toluidine using 4-(4,6-dimethoxy1,3,5-triazin-2-yl)-4-methylmorpholinium toluene-4-sulfonate (DMT/NMM/ $\mathrm{TsO}^{-}$), which was developed by Kamiński and Kolesińska [51,52]. This salt activates carboxylic groups, which in turn could easily react with the amines in the model compound or oligopeptide. Various reagent ratios were tested (see Table 1 in Section 2.3). The samples after coupling were centrifuged and the precipitate was removed. The obtained products, especially $\mathrm{NG} / \mathrm{ca} / \mathrm{T} \mathrm{1/1/1}$, were cloudy; therefore, all the samples were centrifuged. All four coupling products were dialyzed until low-molecular-weight products were removed.

After dialysis, the sizes $\left(R_{h}\right)$ of the model nanocarriers were measured (Table 4$)$ using the DLS technique in water at $\mathrm{pH} \approx 4$. It should be noted that these conditions were different from those used to determine nanogel parameters just after their synthesis (dialyzed samples measured in water instead of non-dialyzed ones in a solution of $0.5 \mathrm{~mol} \cdot \mathrm{dm}^{-3}$ $\mathrm{NaClO}_{4}, \mathrm{pH}$ 10); hence, the size of the non-modified nanogels, NG_I, differed from that listed in Table 3 . The average $R_{h}$ values for all samples were above $100 \mathrm{~nm}$. It is interesting to see that toluidine coupling resulted in a decrease in the nanogel size. This can be interpreted as the result of partial hydrophobization of the initially highly hydrophilic gel particle, which was strongly swollen in water. Hydrophobic interactions between the toluidine groups within the nanogels apparently caused the structure to shrink.

Table 4. Z-average hydrodynamic radius ( \pm standard deviations) for raw nanogels (NG_I) and nanogels coupled with p-toluidine. All samples were measured after dialysis. $\mathrm{pH}$ of the samples during the measurement was in the range of 3.9-4.3.

\begin{tabular}{cc}
\hline Sample & Z-Average $\boldsymbol{R}_{\boldsymbol{h}} \mathbf{( n m )}$ \\
\hline NG_I & $186 \pm 19$ \\
NG/ca/T 1/1/1 & $127 \pm 18$ \\
NG/ca/T 2/1/2 & $109 \pm 7$ \\
NG/ca/T 10/1/10 & $100 \pm 9$ \\
NG/ca/T 10/10/1 & $105 \pm 3$ \\
\hline
\end{tabular}


Physicochemical properties of purified nanogels coupled with p-toluidine were analyzed by FTIR, UV-Vis, and ${ }^{1} \mathrm{H}$ NMR spectroscopy to confirm successful coupling.

Nanocarriers with the model compound were analyzed by FTIR spectroscopy; the spectra of three products of PAA nanogels coupled with p-toluidine were compared with PAA nanogels after dialysis and lyophilization (Figure 2). In the literature, the spectra of PAA [78-80] and p-toluidine [81-83] are well known. The PAA spectrum was characterized by a broad band at $\sim 3140-3190 \mathrm{~cm}^{-1}$ corresponding to O-H stretching, which overlapped with a C-H stretching band near $2960 \mathrm{~cm}^{-1}$ and a separate strong band $1712 \mathrm{~cm}^{-1}$ from $\mathrm{C}=\mathrm{O}$ stretching. Many other smaller bands could be also found: at $1454 \mathrm{~cm}^{-1}$ derived from $\mathrm{CH}_{2}$ deformation vibrations; three bands near $1415 \mathrm{~cm}^{-1}, 1246 \mathrm{~cm}^{-1}$, and $1171 \mathrm{~cm}^{-1}$ that corresponded to $\mathrm{C}-\mathrm{O}$ stretching vibrations coupled with $\mathrm{O}-\mathrm{H}$ in-plane bending; a broad band at $902 \mathrm{~cm}^{-1}$ from O-H out-of-plane bending; and $801 \mathrm{~cm}^{-1}$ from $\mathrm{CH}_{2}$ twisting and $\mathrm{C}-\mathrm{COOH}$ stretching. The spectra of coupling products were similar to those of raw PAA nanogels; however, one can easily distinguish a broad double band near 1515 and $1540 \mathrm{~cm}^{-1}$ that originated from amide II derived mainly from in-plane $\mathrm{N}-\mathrm{H}$ bending and to some extent from $\mathrm{C}-\mathrm{N}$ and $\mathrm{C}-\mathrm{C}$ stretching vibrations, and probably from p-toluidine $\mathrm{C}=\mathrm{C}$ stretching and $\mathrm{NH}_{2}$ bending vibrations $\left(1510,1594\right.$, and $\left.1625 \mathrm{~cm}^{-1}\right)$. The highest intensity of these signals could be observed for the sample NG/ca/T $2 / 1 / 2$, whereas it was significantly weaker for the samples of molar ratios 10/1/10 and 10/10/1. Another characteristic band expected for p-toluidine coupled with nanogels, at ca. $1663 \mathrm{~cm}^{-1}$, was apparently overlapped by the strong $\mathrm{C}=\mathrm{O}$ stretching band of PAA. A closer look at the strong maximum for PAA at $1712 \mathrm{~cm}^{-1}$ reveals that it became wider upon coupling, suggesting some contribution from the $\mathrm{C}=\mathrm{O}$ stretching band of the amide.

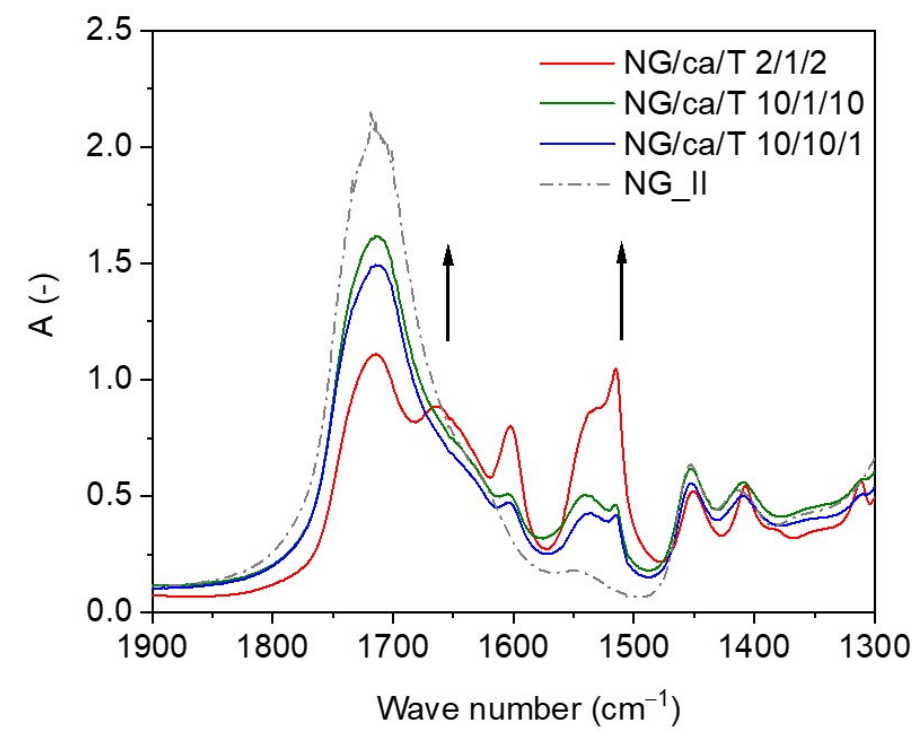

Figure 2. FTIR spectrum of three products of PAA nanogels coupling with p-toluidine $(\mathrm{NG} / \mathrm{ca} / \mathrm{T})$ in different molar ratios: 2/1/2 and 10/10/1, and neat poly(acrylic acid) nanogels (NG_II).

The coupling process was also followed by UV-Vis spectroscopy. The spectra of $0.16 \mathrm{mmol} \cdot \mathrm{dm}^{-3}$ aqueous p-toluidine solution, $\mathrm{pH} 5.5$, showed three bands at 198, 232, and $287 \mathrm{~nm}$ (Figure 3) [84], whereas neat PAA nanogels showed a featureless spectrum with absorbance rising towards the far UV. These two spectra were compared with data obtained for products of the coupling process. Bands for the coupled products were visible in range of 190-325 nm, with the maximum at $198 \mathrm{~nm}$ and $245 \mathrm{~nm}$, which was shifted to $260 \mathrm{~nm}$ for NG/ca/T 1/1/1 sample (Figure 3). Comparing the spectrum of p-toluidine and the coupling products, one can see a certain shift in the bands. The $\mathrm{pH}$ of all samples was set as a value above the $\mathrm{p}$-toluidine $\mathrm{p} K_{a}=5.1$ [85]; hence, these differences did not originate from varying $\mathrm{pH}$ values, but rather from differences in the electronic structure between the 
starting amine and resulting amide, which may have been particularly pronounced in this system due to the aromatic character of the substituent. The peak shifts in the coupling products spectra made it impossible to quantify the content of p-toluidine. Therefore, another method was used to characterize the product samples- ${ }^{1} \mathrm{H}$ NMR spectroscopy.

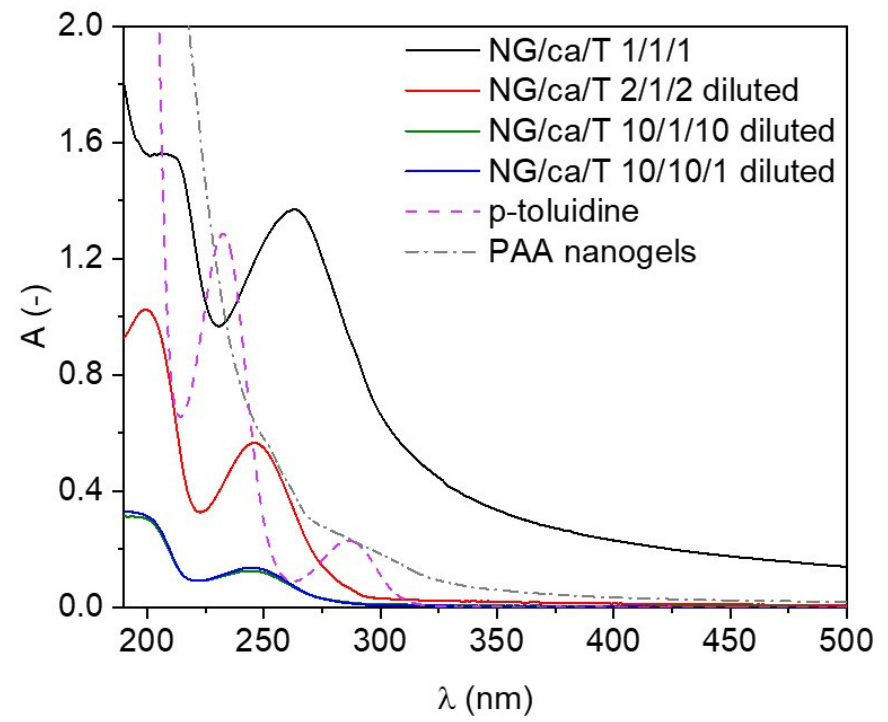

Figure 3. The UV-Vis spectra of four product samples of PAA nanogel coupling with p-toluidine $(\mathrm{NG} / \mathrm{ca} / \mathrm{T})$ in different molar ratios: $1 / 1 / 1(\mathrm{pH} 4.3), 2 / 1 / 2,10 / 1 / 10$, and 10/10/1; the three last samples were diluted $100 \times$ and their $\mathrm{pH}$ was ca. 6 . The pink dashed line corresponds to $0.16 \mathrm{mmol} \cdot \mathrm{dm}^{-3} \mathrm{p}$-toluidine solution, $\mathrm{pH} 5.5$; the grey dotted line corresponds to PAA nanogels after dialysis, $\mathrm{pH} 5.7$.

The ${ }^{1} \mathrm{H}$ NMR spectrum of linear PAA has been studied before [86-88]. The experimental spectrum of the PAA nanogels (Figure 4A) is consistent with those in the literature. High-intensity signal A (1.7 ppm) corresponded to the group $\mathrm{CH}_{2}$ and $\mathrm{B}$ (2.3 ppm) of the $\mathrm{CH}$ protons of poly(acrylic acid) nanogels. The integration of peaks, as in the literature spectrum, gave integral ratios for the poly(acrylic acid) nanogel backbone $\mathrm{H}_{\mathrm{A}}: \mathrm{H}_{\mathrm{B}}=2: 1$. Other bands of low intensity visible in the spectrum may have been a result of polymer chain fragmentation during irradiation, but the bands were so small that they were considered insignificant. The large peak at $4.7 \mathrm{ppm}$ came from water and was visible in each spectrum.

The spectra of the substituted nanogels (PAA nanogels/coupling agent/p-toluidine in molar ratio $10 / 10 / 1$ and 10/1/10, Figure $4 \mathrm{~B}, \mathrm{C}$, respectively) were compared to the neat nanogel spectrum. Both coupling product spectra were very similar to each other. In the spectrum from 1 to $3 \mathrm{ppm}$, several signals came from poly(acrylic acid), doublet (d) of the $-\mathrm{CH}_{2}$ group $(\mathrm{A} ; 1.5 \mathrm{ppm})$, and triplet of the $-\mathrm{CH}$ group $(\mathrm{B}, 2.3 \mathrm{ppm})$. The signals from the aromatic group of p-toluidine (available in the database, recorded in $\mathrm{D}_{2} \mathrm{O}$, $700 \mathrm{MHz}$ ) [89-92] were visible-two doublets E (7.2 ppm) and F (7.1 ppm) and singlet (s) of the $-\mathrm{CH}_{3}$ group D (2.1 ppm). Although exact quantitative analysis was not possible due to the broadening and overlap effects, a rough estimate based on integrating peaks $\mathrm{A}, \mathrm{B}$, and D, as well as E and F, was that for $10 / 10 / 1$ and $10 / 1 / 10, \mathrm{ca} .15 \mathrm{~mol} \%$ and $12 \mathrm{~mol} \%$ of the original carboxylic groups were substituted, not very far from the theoretical yield of ca. $10 \%$. This seems to indicate that the theoretical stoichiometric degree of substitution was achieved and points to somewhat higher coupling efficiency in the case of 10/10/1, in line with the FTIR data in Figure 2. 

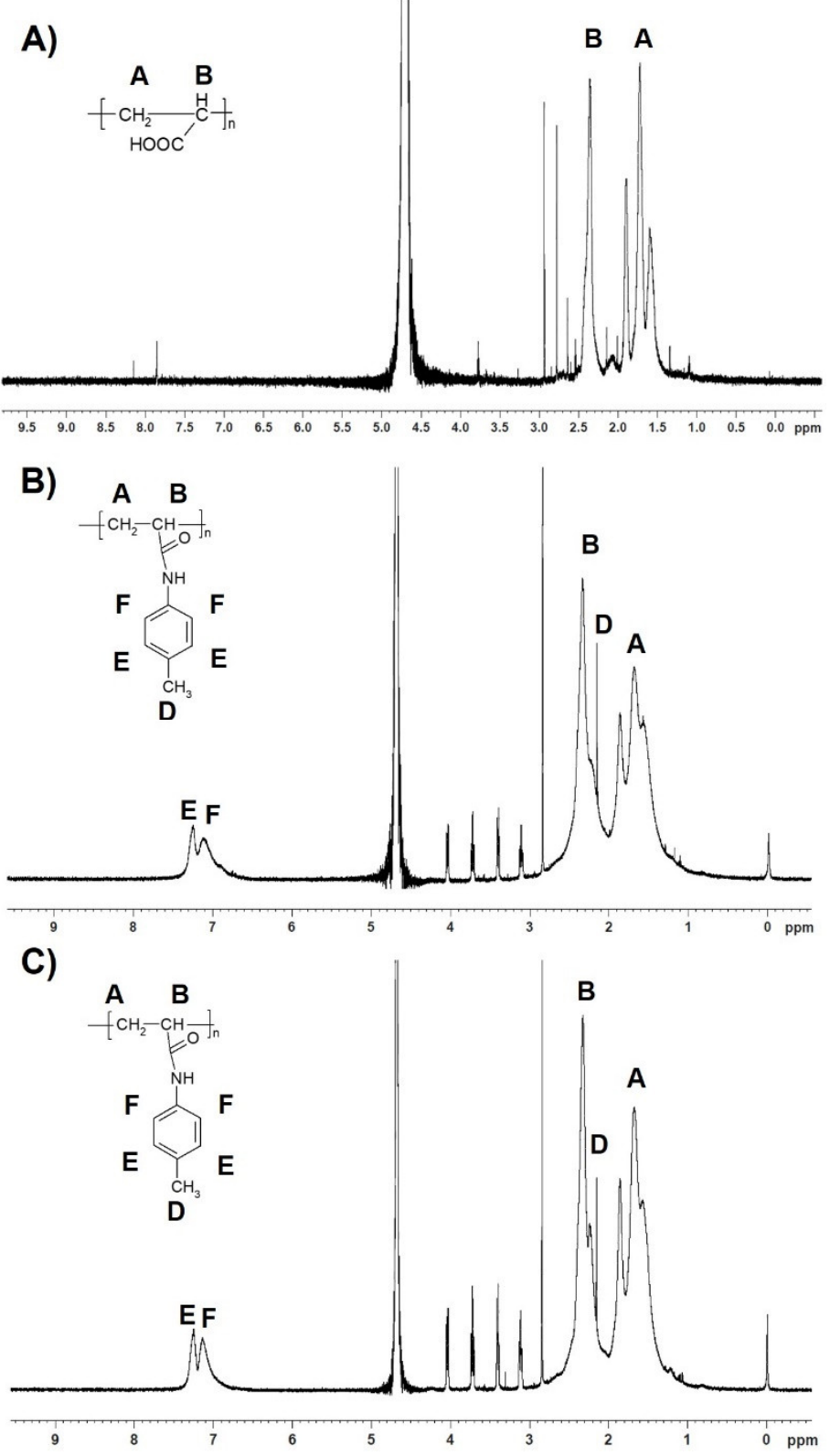

Figure 4. ${ }^{1} \mathrm{H}$ NMR spectra of (A) poly(acrylic acid) nanogels, (B) nanogels of PAA/coupling agent/ptoluidine in molar ratio 10/10/1, and (C) PAA/coupling agent/p-toluidine in a molar ratio of $10 / 1 / 10$ recorded in $\mathrm{D}_{2} \mathrm{O}, 700 \mathrm{MHz}$.

The peaks in the range of 3-4 ppm visible in the spectra in Figure $4 \mathrm{~B}, \mathrm{C}$ were derived from $N$-methylmorpholine (NMM), which was added at the stage of activation of the carboxylic function in order to convert the $\mathrm{COOH}$ group into a carboxylate anion (salt from NMM), which, due to its higher reactivity, is easier to react with condensing reagents to form active forms.

To summarize, the tests on the coupling model compound with PAA nanogels confirmed the effectiveness of described coupling method. The studies show that the molar ratio of PAA nanogels/coupling agent/p-toluidine $1 / 1 / 1$ is too large. The $2 / 1 / 2$ sample also had some precipitation issues, but the UV-Vis and FTIR measurements confirmed that the coupling process was successful. The sample 10/10/1 had the best efficiency in comparison to other samples, with no precipitation effects observed. Somewhat less of the model compound was covalently bound in the sample of PAA nanogels/coupling agent/p-toluidine 10/1/10. Such results were expected, because in the last case 10-fold less 
carboxyl groups were activated than in the case of sample 10/10/1. This is an important indication for further steps in bombesin coupling. Each time the coupling agent was used to activate all carboxylic groups on the nanogels, and only the $\mathrm{COOH}$-oligopeptide ratio was changed.

\subsection{Coupling PAA Nanogels with Oligopeptide}

The next step after coupling the PAA nanogels with the model compound was coupling the nanogels with oligopeptide-bombesin derivative. The studies were performed on two types of oligopeptide (with and without DOTA), originating from two sources: one in-house synthesized (both variants of peptide) and the second supplied by an external company (DOTA-bombesin derivative). All bombesin derivatives were coupled with PAA nanogels using 4-(4,6-dimethoxy-1,3,5-triazin-2-yl)-4-methylmorpholinium toluene-4sulfonate. The experience gained from preliminary studies on the model compound has shown that the best option is the activation of all carboxylic groups of PAA nanogels, so the molar ratio of the nanogels and coupling agent during reaction was fixed. The molar ratio of the carboxylic groups of PAA nanogels to oligopeptide had to be high enough not to change hydrophilic properties of the nanocarriers. Coupling was performed using three different molar ratios of carboxylic groups in PAA nanogels to bombesin derivative: 100/1 (for in-house synthesized-NGBD100H and supplied by external company, DOTA-bombesin derivative-NGBD100E, and one sample without DOTA-NGB100H), 500/1-NGBD500E, and 1000/1-NGBD1000E for the samples of DOTA-bombesin derivative supplied by an external company. The first step in the coupling reaction is the activation of carboxylic groups of PAA nanogels by adding $\mathrm{DMT} / \mathrm{NMM} / \mathrm{TsO}^{-}$and the next step is the final coupling of the oligopeptide with nanogel.

The measurements of dynamic light scattering were performed on the purified samples of nanogels coupled with bombesin-DOTA derivative ( $\mathrm{pH}$ 6.3). Table 5 summarizes the average values of the Z-average hydrodynamic radius. The $R_{h}$ values of the substituted products did not differ significantly from the hydrodynamic radii of their parent nanogels NG_I and NG_II for the "E" and " $\mathrm{H}$ " series, respectively. This could have been due to the relatively low degree of substitution of the carboxylic groups (maximum one bombesin molecule per 100 groups), but also to the two counterbalancing effects of substitutionincrease in the mass (which could have manifested itself as a larger size if all other factors remained unchanged) and decrease in hydrophilicity, which in turn may have caused some de-swelling of the nanogels.

Table 5. The values of the Z-average hydrodynamic radius ( \pm standard deviations) for raw nanogels and nanogels coupled with bombesin-DOTA derivative. All samples were measured after dialysis. "E" series products are based on NG_I batch, "H" series on the NG_II batch of nanogels.

\begin{tabular}{cc}
\hline Sample & Z-Average $\boldsymbol{R}_{\boldsymbol{h}}$ [nm] \\
\hline NG_I & $186 \pm 19$ \\
NGBD100E & $212 \pm 36$ \\
NGBD500E & $176 \pm 19$ \\
NGBD1000E & $217 \pm 25$ \\
NG_II & $113 \pm 43$ \\
NGBD100H & $102 \pm 9$ \\
NGB100H & $145 \pm 1$ \\
\hline
\end{tabular}

In order to confirm the coupling of the nanogels to the bombesin derivative, FTIR, UV-Vis, fluorescence, and ${ }^{1} \mathrm{H}$ NMR spectroscopy were employed. The FTIR spectrum of the PAA nanogels was discussed in Section 3.2, and in Figure 5 it is compared with all the coupling products. According to the literature, bombesin-DOTA derivative has two characteristic bands: at $3299 \mathrm{~cm}^{-1}$ free amine groups, at $1647 \mathrm{~cm}^{-1}$ carbonyl groups of the peptide bonds (amide I), and at $1533 \mathrm{~cm}^{-1} \mathrm{CN}$ (amide II) [93,94]. The band of bombesinDOTA derivative amine groups was overlayed by $\mathrm{O}-\mathrm{H}$ stretching and $\mathrm{C}-\mathrm{H}$ stretching PAA 
bands. The strong maximum at $1712 \mathrm{~cm}^{-1}$ from the $\mathrm{C}=\mathrm{O}$ stretching bands of the carboxylic groups of the nanogels overlapped with the carbonyl groups of the peptide bond and amide I band near $1665 \mathrm{~cm}^{-1}$. In this region, the signal from the carbonyl groups of DOTA should also have been visible at $1734 \mathrm{~cm}^{-1}$ [95]. The only characteristic feature of the peptide that was not overlayed by the PAA signals was a band at $1547 \mathrm{~cm}^{-1}$, derived from amide II, representing the amide group formed by coupling the nanogels with the oligopeptide and bombesin-DOTA derivative CN groups. The intensity of the amide II bands for the spectra of the PAA nanogels coupled with bombesin-DOTA derivative in the ratio of 100/1 (samples NGBD100E, NGBD100H, Figure 5) was the highest, and for these samples the band near $1712 \mathrm{~cm}^{-1}$ was also wider than for PAA, confirming the presence of amide I. The intensity of these bands was much lower for the samples with significantly smaller amounts of bombesin-DOTA derivative introduced into the reaction (Figure 5).

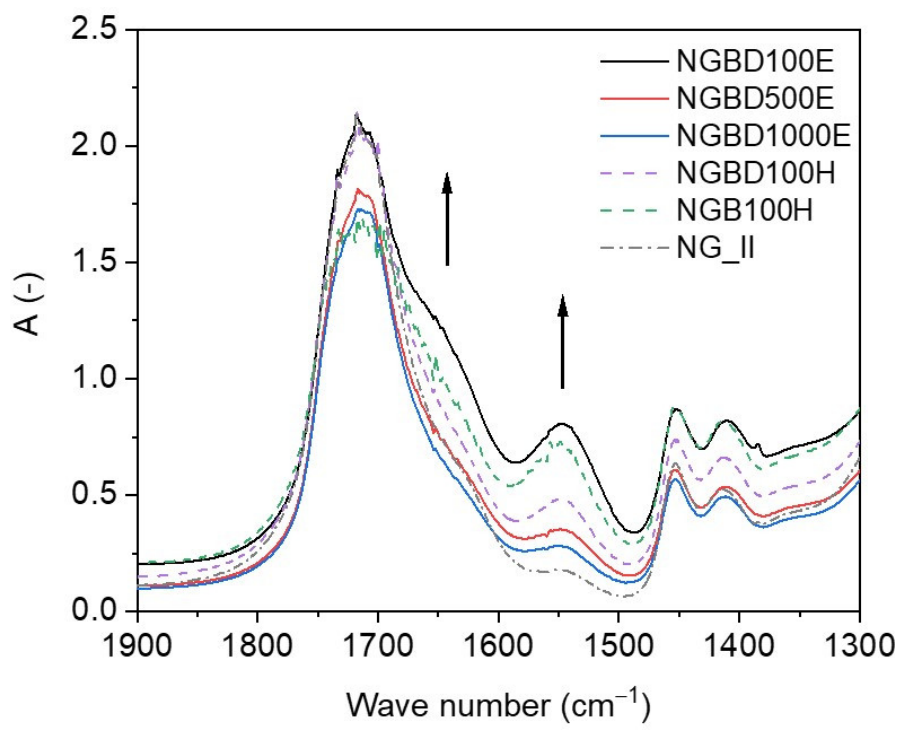

Figure 5. FTIR spectra of neat and bombesin-substituted PAA nanogels NG_II (sample codes—see Table 2).

In Figure 6, the UV-Vis spectrum of a representative sample-a nanocarrier obtained by coupling PAA nanogels with DOTA-bombesin derivative in the molar ratio of 100/1 (NGBD100E)-is compared to the spectra of the substrates: DOTA-bombesin derivative and raw purified PAA nanogels ( $\mathrm{pH} 3.8$, concentration after dialysis ca. $1.01 \mathrm{~g} \cdot \mathrm{L}^{-1}$ ). Although the nanogel spectrum was broad and featureless, the DOTA-bombesin exhibited three characteristic overlapping bands at $273 \mathrm{~nm}, 280 \mathrm{~nm}$, and $289 \mathrm{~nm}$, in agreement with the literature data [94]. These bands were also present in the spectra of nanogels coupled with bombesin-DOTA. Based on the absorbance at $280 \mathrm{~nm}$ after subtraction of the absorbance of pure nanogels, one can estimate the content of bombesin-DOTA in the products (Table 6). Although this estimate is not a precise one (which can be seen from one of the results exceeding $100 \%$ ), some conclusions can be drawn. In general, the coupling efficiencies were reasonably high, especially taking into account the fact that some carboxylic groups in the nanogel structure might have been less easy to reach or even less sterically suitable for coupling. On average, somewhat higher coupling efficiency was reached for samples where relatively high amounts of bombesin was used in the coupling reaction, whereas for the NGBD1000E sample (lowest amount of bombesin) the lowest value was observed. 


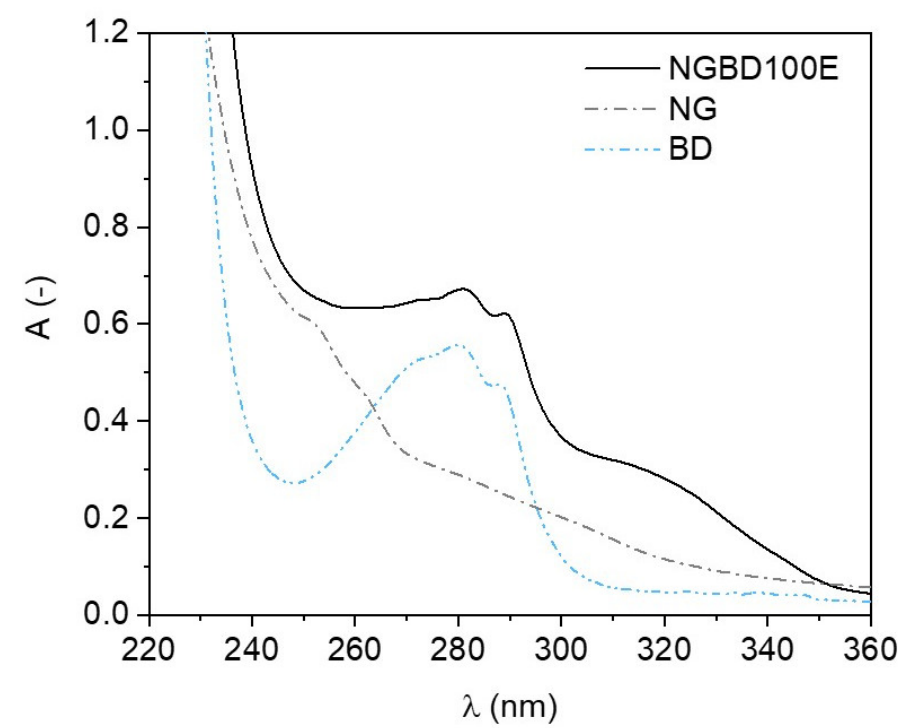

Figure 6. UV-Vis spectra of the substrates- $0.367 \mathrm{~g} \cdot \mathrm{L}^{-1}$ DOTA-bombesin derivative (BD), raw purified PAA nanogels after dialysis, $\mathrm{pH} 3.8$ (NG), and the coupling product-nanocarrier obtained from coupling PAA nanogels with DOTA-bombesin derivative in a molar ratio of 100/1 (NGBD100E), pH 6.3.

Table 6. The efficiency of the coupling process estimated from the UV-Vis data. Different expected bombesin concentration values for samples with the same molar ratio result from differences in the volume of the solution (dialysis effect).

\begin{tabular}{cccc}
\hline Sample & $\begin{array}{c}\text { Expected Bombesin } \\
\text { Concentration } \\
\text { at 100\% Efficiency } \\
(\mathbf{m g} / \mathbf{m L})\end{array}$ & $\begin{array}{c}\text { Estimated Bombesin } \\
\text { Concentration } \\
\text { from UV-Vis Data } \\
\mathbf{( m g / m L )}\end{array}$ & $\begin{array}{c}\text { Approximate } \\
\text { Coupling Efficiency } \\
\mathbf{( \% )}\end{array}$ \\
\hline NGBD100E & 0.281 & 0.252 & 90 \\
NGBD500E & 0.061 & 0.067 & 111 \\
NGBD1000E & 0.031 & 0.015 & 47 \\
NGBD100H & 0.313 & 0.203 & 65 \\
NGB100H & 0.202 & 0.105 & 52 \\
\hline
\end{tabular}

The results from the absorption spectra were supplemented with fluorescence measurements. First, the substrates used for coupling were measured. The maximum intensity on the fluorescence emission spectra of DOTA-bombesin derivative was at ca. $350 \mathrm{~nm}$ (see Figure 7), which corresponds to the tryptophan maximum at ca. $350 \mathrm{~nm}$ in water $[96,97]$. The spectrum of DOTA-bombesin derivative (concentration $0.367 \mathrm{~g} \cdot \mathrm{L}^{-1}$ ) was reduced 10 -fold for clarity $(\mathrm{BD} 10 \times)$. The emission intensity of neat PAA nanogels (concentration $1.01 \mathrm{~g} \cdot \mathrm{L}^{-1}$ ) was minor in comparison to other samples. The spectrum of nanogels derivatized with DOTA-bombesin NGBD100H (a representative sample) exhibited a relatively strong signal with a maximum at $350 \mathrm{~nm}$, thus confirming successful coupling. These measurements confirm that the conjugation process was successful; however, quantitative determination of $\mathrm{BN}$ in the samples was not attempted, considering the lack of additivity of fluorescence. 


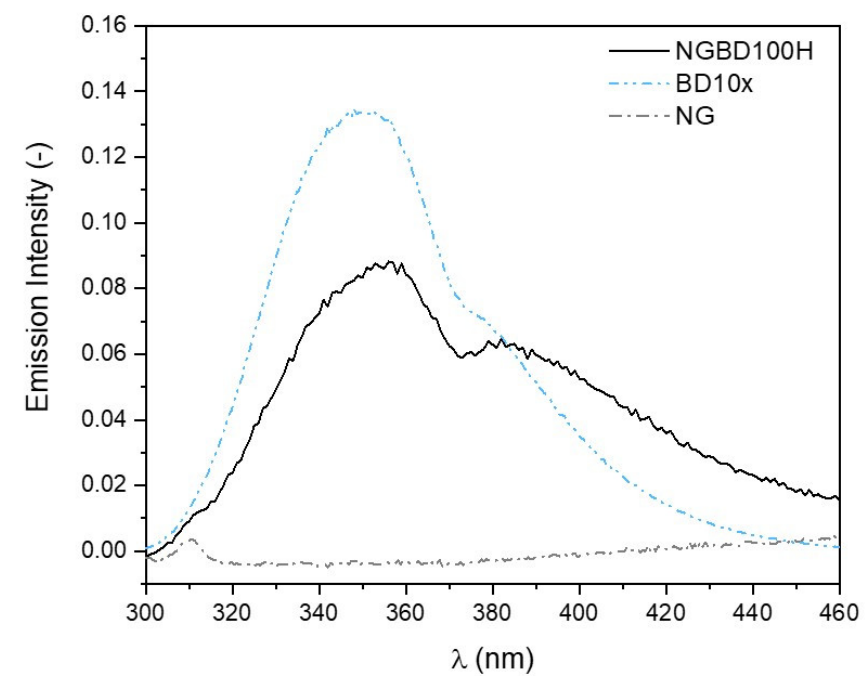

Figure 7. Emission fluorescence spectra of the substrates- $0.367 \mathrm{~g} \cdot \mathrm{L}^{-1}$ DOTA-bombesin derivative (BD) (signal intensity was reduced 10-fold in the graph), raw PAA nanogels (NG), and of the productnanocarriers obtained by coupling PAA nanogels with DOTA-bombesin derivative, NGBD100H (for sample codes, see Table 2).

The fluorescence decays for the abovementioned systems were biexponential, with almost the same lifetimes and amplitudes. The average fluorescence lifetime was in the range of 1.83-1.92 ns and was shorter than that measured for L-tryptophan (2.64 ns). The two lifetimes of the fluorescence of tryptophan are due to two sub-structures existing in its excited state and are intrinsic to tryptophan independently of the solvent. It seems that tryptophan moiety within nanogels is not significantly affected by the local microenvironment.

In Section 3.2, the ${ }^{1} \mathrm{H}$ NMR spectrum of neat PAA nanogels was compared with the spectra of nanogels coupled with the model compound. Successful coupling was confirmed by the presence of signals from p-toluidine protons of the aromatic group visible above $7 \mathrm{ppm}$. Here the spectrum of raw nanogels (Figure 8A) was compared with nanogels coupled with bombesin-DOTA derivative in the molar ratio of 100/1, sample NGBD100E (Figure $8 \mathrm{~B})$. The highest intensity signals were from the $\mathrm{CH}_{2}(\mathrm{~d}, 1.70 \mathrm{ppm})$ and $\mathrm{CH}$ groups ( $t, 2.33 \mathrm{ppm}$ ) of the PAA nanogels. The signals from the aliphatic chain of oligopeptide (in the range 0.7-4.5 ppm) and DOTA bands (near 3-4 ppm) were partially overlayed by poly(acrylic acid); therefore, it was difficult to assign all the signals corresponding to the appropriate protons. In the literature, the ${ }^{1} \mathrm{H}$ NMR spectra of bombesin [98,99] and DOTA [100] and the signal assignments are well known. Based on that, despite the low intensity of bombesin- and DOTA-derived signals on our spectrum, it was possible to identify many of them. The most characteristic bands were those derived from aromatic His-12 (2H, s, 8.45 ppm and 4H, s, 7.17 ppm) and Trp-8 (many signals from 2H, s, 5H, $\mathrm{d}, 6 \mathrm{H}, \mathrm{t}, 7 \mathrm{H}, \mathrm{t}, 8 \mathrm{H}, \mathrm{d}$, all in the range of 7.15-7.45 ppm). On the basis of the obtained spectrum, the following amino acid signals could be read: Met-14 ( $\alpha-\mathrm{CH}, \mathrm{t}, 4.40 \mathrm{ppm})$, Leu-13 and Leu-4 ( $\alpha-\mathrm{CH}, \mathrm{t}, 4.40$ ppm), Gln-2 ( $\alpha-\mathrm{CH}, \mathrm{t}, 4.36$ ppm), Ala-9 ( $\alpha-\mathrm{CH}$, quartet, 4.20 ppm), Gln-7 ( $\alpha-\mathrm{CH}, \mathrm{t}, 4.10 \mathrm{ppm})$, Val-10 ( $\alpha-\mathrm{CH}, \mathrm{d}, 4.00 \mathrm{ppm}), \mathrm{Gly}-5$ and Gly-11 $(\alpha-\mathrm{CH}$, $\mathrm{s}, 3.85$ ppm), His-12 ( $\left.\beta-\mathrm{CH}_{2}, \mathrm{~d}, 3.10 \mathrm{ppm}\right), \operatorname{Trp}-8\left(\beta-\mathrm{CH}_{2}, \mathrm{~d}, 3.08 \mathrm{ppm}\right)$, Lys-1 and Lys-3 $\left(\varepsilon-\mathrm{CH}_{2}, \mathrm{t}, 2.98 \mathrm{ppm}\right)$, Asn-6 $\left(\beta-\mathrm{CH}_{2}, \mathrm{~d}, 2.69 \mathrm{ppm}\right)$, Met-14 $\left(\gamma-\mathrm{CH}_{2}, \mathrm{t}, 2.60 \mathrm{ppm} ; \varepsilon-\mathrm{CH}_{3}\right.$, s, $2.08 \mathrm{ppm})$, Val-10 ( $\beta-\mathrm{CH}, \mathrm{o}, 2.05 \mathrm{ppm}), \mathrm{Gln}-2$ and $\mathrm{Gln}-7\left(\beta-\mathrm{CH}_{2}\right.$, quartet, $\left.2.00 \mathrm{ppm}\right)$, Ala-9 $\left(\beta-\mathrm{CH}_{3}, \mathrm{~d}, 1.30 \mathrm{ppm}\right)$, Lys -1 and Lys-3 $\left(\gamma-\mathrm{CH}_{2}\right.$, quintet, $\left.1.35 \mathrm{ppm}\right)$, Val-10 $\left(\gamma-\mathrm{CH}_{3}\right.$, d, $0.90 \mathrm{ppm})$, and Leu-4 and Leu-13 $\left(\delta-\mathrm{CH}_{3}, \mathrm{~d}, 0.80-0.90 \mathrm{ppm}\right)$. Signals from the DOTA protons were visible between the amino acids in the region of 3-4 ppm: $\mathrm{CH}_{2}$ groups inside the ring ( $\mathrm{t}, 3.73 \mathrm{ppm}, \mathrm{t}, 3.65 \mathrm{ppm}, \mathrm{t}, 3.12-3.18 \mathrm{ppm})$ and $\alpha-\mathrm{CH}$ groups next to carboxylic groups (s, 4.06 ppm, s, 4.04, s, 3.43 ppm, s, 3.41 ppm). 
A)
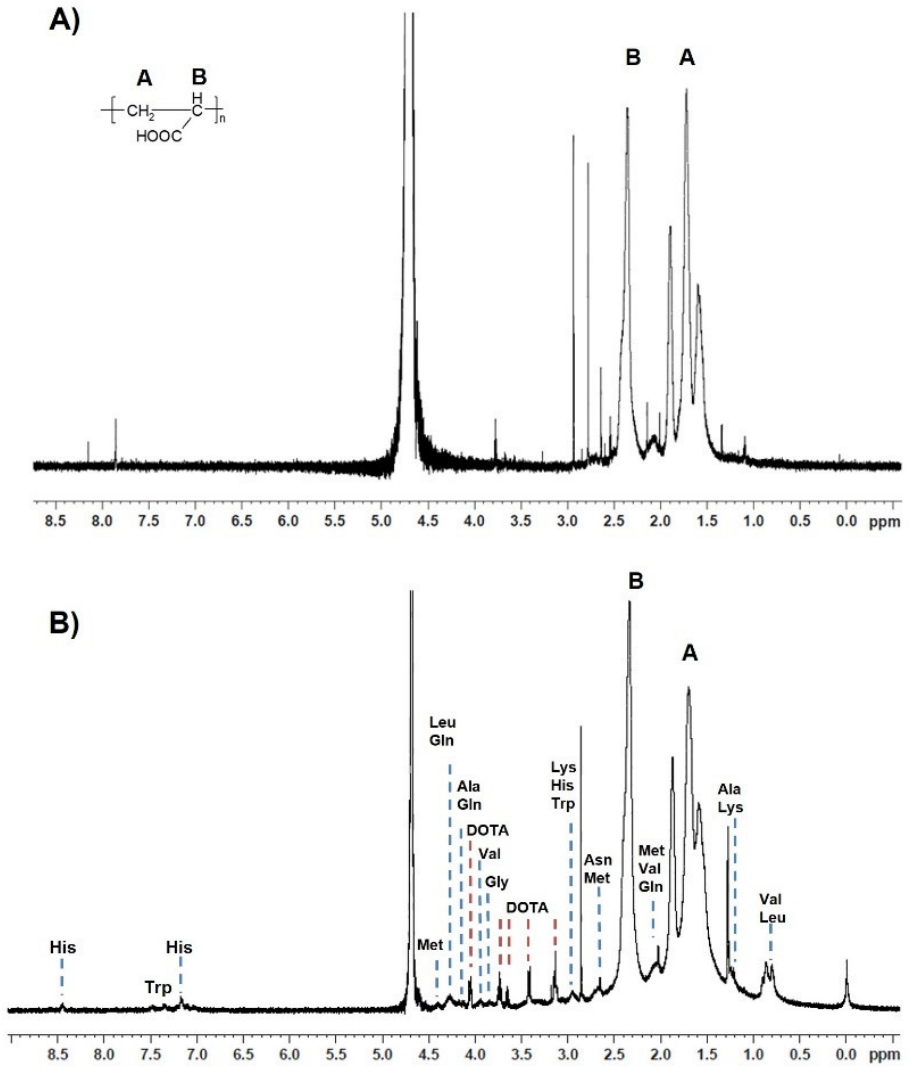

Figure 8. ${ }^{1} \mathrm{H}$ NMR spectra of (A) poly(acrylic acid) nanogels, (B) nanogels of PAA/bombesin-DOTA derivative in the molar ratio of $100 / 1$, sample NGBD100E, recorded in $\mathrm{D}_{2} \mathrm{O}, 700 \mathrm{MHz}$. Single amino acids signals are presented with blue dashed lines and DOTA signals with brown dashed lines.

\subsection{Radiolabeling of DOTA-Bombesin Derivative}

The radiolabeling study revealed that PAA nanogels coupled with derivative could be effectively labeled with lutetium-177. All of the NGBD derivatives were studied for labeling in the same conditions. The summarized results of the study are presented in Table 7.

Table 7. The radiochemical yield (\%) of the PAA nanogel samples coupled with DOTA-bombesin derivatives and raw nanogels after the purification process.

\begin{tabular}{ccccc}
\hline & NGBD100E & NGBD500E & NGBD1000E & NG \\
\hline NGBD:Lu & 13.9 & 3.7 & 0.8 & 0 \\
{$[$ mol:mol $]$} & $98.1 \pm 0.7$ & $57.4 \pm 5.3$ & $8.1 \pm 0.6$ & $0.7 \pm 0.1$ \\
{$\left[{ }^{177} \mathrm{Lu}\right] \mathrm{Lu}-$ sample } & $0.0 \pm 0.0$ & $0.0 \pm 0.0$ & $0.0 \pm 0.0$ & $0.0 \pm 0.0$ \\
{$\left[{ }^{177} \mathrm{Lu}\right] \mathrm{Lu}-\mathrm{BD}$} & $2.0 \pm 0.6$ & $42.6 \pm 5.3$ & $91.9 \pm 0.6$ & $99.3 \pm 0.1$ \\
{$\left[{ }^{177} \mathrm{Lu}\right] \mathrm{Lu}$ free } & &
\end{tabular}

The amount of lutetium-177 used for the NGBD labeling was constant for all labeling experiments calculated as 1:1, basing on the expected molar amount of bombesin conjugated to the NGBD1000E nanoparticles. In theory, assuming ideal conditions (no DOTA conjugating metals competing with lutetium and no steric hindrance), the labeling yield for NGBD1000E should be near $100 \%$. In the experiment, a good $>95 \%$ radiolabeling yield was achieved for NGBD100E, where the BD's molar ratio to lutetium was almost 14 . Basing on the experimental data, the optimal ratio of the chelating moiety to the lutetium (around 6.5) was calculated based on the linear regression equation. The curve is presented in Figure 9. 


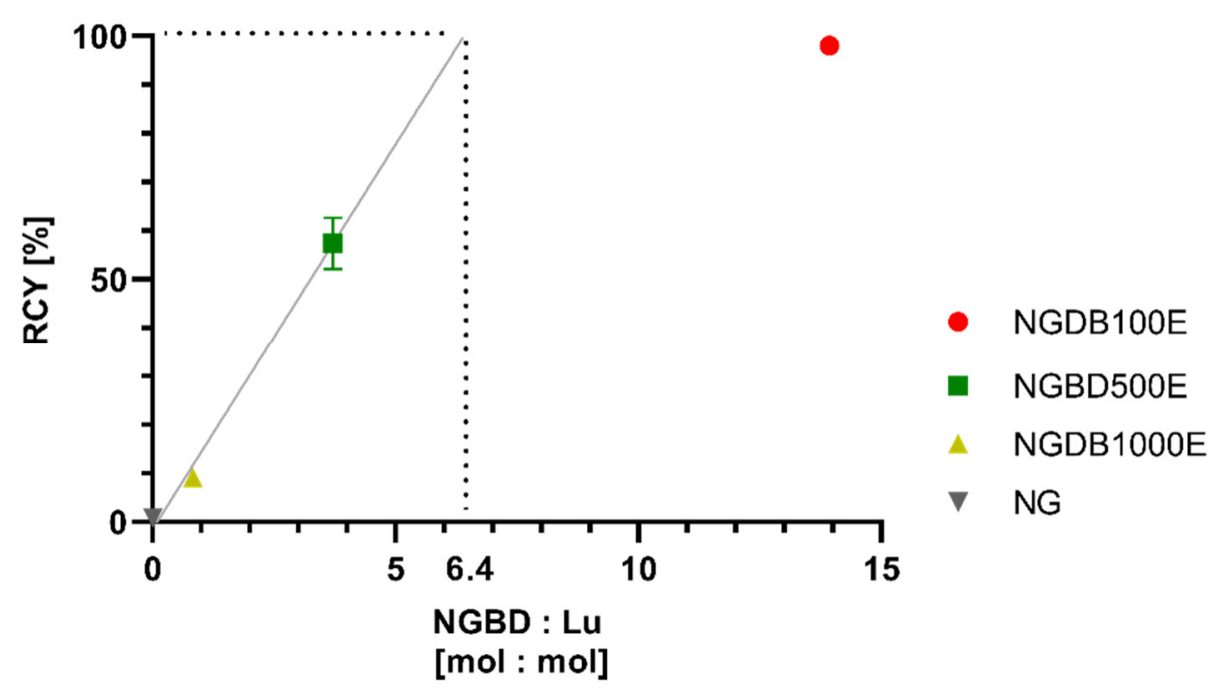

Figure 9. Lutetium-177 radiolabeling yield of NGBD particles $\left(0.73+/-0.04 \mathrm{GBq} \mathrm{mg}^{-1} \mathrm{NGBD}\right)$ in the function of the calculated BD-to-Lu ratio. The figure presents the estimation of the optimal NGBD-to-Lu ratio of 6.4, enabling radiolabeling with $100 \%$ yield.

The lower-than-expected labeling yield may have been caused by some steric hindrances affecting accessibility for the radioisotope of the DOTA chelator on the bombesin chain. Another possible cause of the decreased labeling yield may have been a few labeled samples being contaminated with a trace amount of metals such as iron, copper, lead, or zinc.

The labeling of native nanogels ( $\mathrm{RCY}=0 \%$ ) confirmed the specificity of the labeling with the attached $\mathrm{BD}$. The reaction confirmed that weak interactions between carboxyl groups of nanogel, as well as the sponge-like structure of particles, do not lead to nonspecific ${ }^{177}$ Lu uptake.

In the second part of the labeling experiments, the labeling of NGBD100E with increasing $\left[{ }^{177} \mathrm{Lu}\right] \mathrm{LuCl}_{3}$ specific activity (SA) was studied. The results confirmed previous findings that the labeling yield decreases with the increase in activity used. When the molar excess of conjugated BD to lutetium was 2.5, the labeling yield decreased to $20 \%$. In that case, high specific activity of $2.7 \mathrm{GBq} \mathrm{mg}^{-1}$ nanoparticles could only be achieved after purification of the labeling mixture. The maximum SA that could be achieved without purification was ca. $1 \mathrm{GBq} \mathrm{mg}^{-1}$ of NGBD100E. The summarized data are presented in Table 8.

Table 8. Radiochemical yield (\%) as a function of SA for sample PAA nanogels coupled with DOTAbombesin derivative in a molar ratio of 100/1 (sample NGBD100E).

\begin{tabular}{|c|c|c|c|c|c|}
\hline & \multicolumn{5}{|c|}{ Activity for Labeling (GBq $\mathrm{mg}^{-1}$ ) } \\
\hline & 19.64 & 9.31 & 0.78 & 0.68 & 0.18 \\
\hline $\begin{array}{c}\text { BD:Lu [mol:mol] } \\
\left.\text { [ }{ }^{177} \mathrm{Lu}\right] \mathrm{Lu}-\mathrm{NGBD} 100 \mathrm{E}[\%] \\
\left.\text { SA [GB mg }{ }^{-1}\right]\end{array}$ & $\begin{array}{c}1.3 \\
13.8 \pm 1.2 \\
2.71\end{array}$ & $\begin{array}{c}2.5 \\
20.2 \pm 1.7 \\
1.88\end{array}$ & $\begin{array}{l}21.7 \\
99.0 \pm 1.1 \\
0.77\end{array}$ & $\begin{array}{c}56.5 \\
98.1 \pm 0.7 \\
0.67\end{array}$ & $\begin{array}{c}141 \\
99.5 \pm 0.7 \\
0.18\end{array}$ \\
\hline
\end{tabular}

\section{Conclusions}

Despite significant developments in the field of cancer management, there is a constant demand for better diagnostic and treatment options. New perspectives open along with the development of nanotechnology, as nanomaterials have the potential to improve the properties of the currently used drugs (i.e., their solubility and stability), prolong the time they reside in the bloodstream, and help to reduce the side effects of the therapy. Moreover, nanomaterials offer remarkable added value — sophisticated design, including diagnostic modalities, may render these formulations theranostic, i.e., combine diagnosis and treatment. 
The presented work summarizes the efforts aimed at the application of radiationderived poly(acrylic acid) nanogels as targeted nanocarriers of theranostic radioisotopes. The challenge of coupling nanogels with DOTA-bombesin derivative was successfully approached by the use of an innovative coupling strategy, designed according to the concept of "superactive esters," based on DMT/NMM/ $\mathrm{TsO}^{-}$. This strategy was also proven to be suitable for the complete in-house synthesis of our advanced targeting ligand. The obtained DOTA-bombesin nanocarriers showed excellent physicochemical properties and radiolabeling characteristics - high radiochemical yield was achieved upon complexation of lutetium- 177 by the DOTA present in the nanocarrier. Overall, the presented research provides a proof-of-concept for the synthesis and functionalization of radiation-derived nanogel for theranostic applications and paves the way to further development for preclinical use.

Author Contributions: Conceptualization and methodology, S.K., M.W., U.K., M.M. (Michał Maurin), B.K., and P.U.; investigation, M.M. (Małgorzata Matusiak), S.K., M.W., U.K., and M.M. (Michał Maurin); formal analysis, M.M. (Małgorzata Matusiak), B.P.R., S.K., U.K., and M.M. (Michał Maurin); validation, S.K., M.W., U.K., M.M. (Michał Maurin), B.K., and P.U.; supervision, S.K., M.W., B.K., and P.U.; visualization, M.M. (Małgorzata Matusiak), B.P.R., U.K., and M.M. (Michał Maurin); writing—original draft preparation, M.M. (Małgorzata Matusiak), B.P.R., M.W., U.K., and M.M. (Michał Maurin); writing-review and editing, M.M. (Małgorzata Matusiak), B.P.R., S.K., M.W., U.K., M.M. (Michał Maurin), B.K., and P.U. All authors have read and agreed to the published version of the manuscript.

Funding: This work was supported by the International Atomic Energy Agency in the framework of the Coordinated Research Project F22064 (Research Contract No. 18354), the National Science Centre, Poland (Grants no. 2019/33/B/ST5/02125 and 2017/27/N/ST4/02536), and National Center of Research and Development (Warsaw, Poland) in the framework of the project InterChemMed (POWR.03.02.00-00-I029/16), co-funded by the European Social Fund.

Institutional Review Board Statement: Not applicable.

Informed Consent Statement: Not applicable.

Data Availability Statement: The data presented in this study are available on request from the corresponding author.

Conflicts of Interest: The authors declare no conflict of interest. The funders had no role in the design of the study; in the collection, analyses, or interpretation of data; in the writing of the manuscript, or in the decision to publish the results.

\section{References}

1. Mishra, D.K.; Balekar, N.; Mishra, P.K. Nanoengineered strategies for siRNA delivery: From target assessment to cancer therapeutic efficacy. Drug Deliv. Transl. Res. 2017, 7, 346-358. [CrossRef] [PubMed]

2. Shi, J.; Kantoff, P.W.; Wooster, R.; Farokhzad, O.C. Cancer nanomedicine: Progress, challenges and opportunities. Nat. Rev. Cancer 2017, 17, 20-37. [CrossRef] [PubMed]

3. Kumari, P.; Ghosh, B.; Biswas, S. Nanocarriers for cancer-targeted drug delivery. J. Drug Target. 2016, 24, 179-191. [CrossRef]

4. Ocampo-García, B.; Gibbens-Bandala, B.; Morales-Avila, E.; Melendez-Alafort, L.; Khoobchandani, M.; Trujillo-Nolasco, M.; Katti, K. V Dual-targeted therapy and molecular imaging with radiolabeled nanoparticles. In Biotechnology Products in Everyday Life; Khoobchandani, M., Saxena, A., Eds.; Springer International Publishing: Cham, Switzerland, 2019; pp. 201-219. ISBN 978-3-319-92399-4.

5. Bansal, R.; Nagórniewicz, B.; Prakash, J. Clinical advancements in the targeted therapies against liver fibrosis. Mediat. Inflamm. 2016, 2016, 1-16. [CrossRef] [PubMed]

6. Lee, D.S. Radionanomedicine: Combined Nuclear and Nanomedicine, 1st ed.; Lee, D.S., Ed.; Springer International Publishing: Cham, Switzerland, 2018; ISBN 978-3-319-67719-4.

7. Alemán, J.; Chadwick, A.V.; He, J.; Hess, M.; Horie, K.; Jones, R.G.; Kratochvíl, P.; Meisel, I.; Mita, I.; Moad, G.; et al. Definitions of terms relating to the structure and processing of sols, gels, networks, and inorganic-organic hybrid materials (IUPAC recommendations 2007). Pure Appl. Chem. 2007, 79, 1801-1829. [CrossRef]

8. Neamtu, I.; Rusu, A.G.; Diaconu, A.; Nita, L.E.; Chiriac, A.P. Basic concepts and recent advances in nanogels as carriers for medical applications. Drug Deliv. 2017, 24, 539-557. [CrossRef] [PubMed] 
9. Sabatino, M.A.; Ditta, L.A.; Conigliaro, A.; Dispenza, C. A multifuctional nanoplatform for drug targeted delivery based on radiation-engineered nanogels. Radiat. Phys. Chem. 2018, 169, 108059. [CrossRef]

10. Argentiere, S.; Blasi, L.; Ciccarella, G.; Barbarella, G.; Cingolani, R.; Gigli, G. Synthesis of poly(acrylic acid) nanogels and application in loading and release of an oligothiophene fluorophore and its bovine serum albumin conjugate. Macromol. Symp. 2009, 281, 69-76. [CrossRef]

11. Argentiere, S.; Blasi, L.; Morello, G.; Gigli, G. A novel pH-responsive nanogel for the controlled uptake and release of hydrophobic and cationic solutes. J. Phys. Chem. C 2011, 115, 16347-16353. [CrossRef]

12. Kabanov, A.V.; Vinogradov, S.V. Nanogels as pharmaceutical carriers: Finite networks of infinite capabilities. Angew. Chemie Int. Ed. 2009, 48, 5418-5429. [CrossRef]

13. Soni, K.S.; Desale, S.S.; Bronich, T.K. Nanogels: An overview of properties, biomedical applications and obstacles to clinical translation. J. Control. Release 2016, 240, 109-126. [CrossRef]

14. Dispenza, C.; Spadaro, G.; Jonsson, M. Radiation engineering of multifunctional nanogels. Top. Curr. Chem. 2016, $374,1-26$. [CrossRef] [PubMed]

15. Pillai, J.J.; Thulasidasan, A.K.T.; Anto, R.J.; Chithralekha, D.N.; Narayanan, A.; Kumar, G.S.V. Folic acid conjugated cross-linked acrylic polymer (FA-CLAP) hydrogel for site specific delivery of hydrophobic drugs to cancer cells. J. Nanobiotechnol. 2014, 12, 1-9. [CrossRef]

16. Kulhari, H.; Pooja, D.; Singh, M.K.; Kuncha, M.; Adams, D.J.; Sistla, R. Bombesin-conjugated nanoparticles improve the cytotoxic efficacy of docetaxel against gastrin-releasing but androgen-independent prostate cancer. Nanomedicine 2015, 10, 2847-2859. [CrossRef] [PubMed]

17. Adamo, G.; Grimaldi, N.; Campora, S.; Bulone, D.; Bondì, M.L.; Al-Sheikhly, M.; Sabatino, M.A.; Dispenza, C.; Ghersi, G. Multi-functional nanogels for tumor targeting and redox-sensitive drug and siRNA delivery. Molecules 2016, 21, 1594. [CrossRef]

18. Zhang, X.; Malhotra, S.; Molina, M.; Haag, R. Micro- and nanogels with labile crosslinks-from synthesis to biomedical applications. Chem. Soc. Rev. 2015, 44, 1948-1973. [CrossRef]

19. Chacko, R.T.; Ventura, J.; Zhuang, J.; Thayumanavan, S. Polymer nanogels: A versatile nanoscopic drug delivery platform. Adv. Drug Deliv. Rev. 2012, 64, 836-851. [CrossRef] [PubMed]

20. Kadlubowski, S.; Ulanski, P.; Rosiak, J.M. Synthesis of tailored nanogels by means of two-stage irradiation. Polymer 2012, 53, 1985-1991. [CrossRef]

21. Henke, A.; Kadlubowski, S.; Ulanski, P.; Rosiak, J.M.; Arndt, K.-F. Radiation-induced cross-linking of polyvinylpyrrolidonepoly(acrylic acid) complexes. Nucl. Instrum. Methods Phys. Res. Sect. B Beam Interact. Mater. Atoms 2005, 236, 391-398. [CrossRef]

22. Schmidt, T.; Janik, I.; Kadlubowski, S.; Ulanski, P.; Rosiak, J.M.; Reichelt, R.; Arndt, K.-F. Pulsed electron beam irradiation of dilute aqueous poly(vinyl methyl ether) solutions. Polymer 2005, 46, 9908-9918. [CrossRef]

23. Kadlubowski, S.; Grobelny, J.; Olejniczak, W.; Cichomski, M.; Ulanski, P. Pulses of fast electrons as a tool to synthesize poly(acrylic acid) nanogels. Intramolecular cross-linking of linear polymer chains in additive-free aqueous solution. Macromolecules 2003, 36, 2484-2492. [CrossRef]

24. Ulanski, P.; Rosiak, J.M. The use of radiation technique in the synthesis of polymeric nanogels. Nucl. Instrum. Methods Phys. Res. Sect. B Beam Interact. Mater. Atoms 1999, 151, 356-360. [CrossRef]

25. Ulanski, P.; Janik, I.; Rosiak, J.M. Radiation formation of polymeric nanogels. Radiat. Phys. Chem. 1998, 52, 289-294. [CrossRef]

26. Matusiak, M.; Kadlubowski, S.; Ulanski, P. Radiation-induced synthesis of poly(acrylic acid) nanogels. Radiat. Phys. Chem. 2018, 142, 125-129. [CrossRef]

27. Ulanski, P.; Kadlubowski, S.; Rosiak, J.M. Synthesis of poly(acrylic acid) nanogels by preparative pulse radiolysis. Radiat. Phys. Chem. 2002, 63, 533-537. [CrossRef]

28. Munavirov, B.; Gnezdilov, O.; Rudakova, M.; Antzutkin, O.N.; Filippov, A. Interaction of polyacrylic acid with lipid bilayers: Effect of polymer mass. Magn. Reson. Chem. 2013, 51, 750-755. [CrossRef]

29. Munavirov, B.V.; Filippov, A.V.; Rudakova, M.A.; Antzutkin, O.N. Polyacrylic acid modifies local and lateral mobilities in lipid membranes. J. Dispers. Sci. Technol. 2014, 35, 848-858. [CrossRef]

30. Yessine, M.-A.; Leroux, J.-C. Membrane-destabilizing polyanions: Interaction with lipid bilayers and endosomal escape of biomacromolecules. Adv. Drug Deliv. Rev. 2004, 56, 999-1021. [CrossRef]

31. Fujiwara, M.; Grubbs, R.H.; Baldeschwieler, J.D. Characterization of pH-dependent poly(acrylic acid) complexation with phospholipid vesicles. J. Colloid Interface Sci. 1997, 185, 210-216. [CrossRef]

32. Chieng, Y.Y.; Chen, S.B. Interaction between poly(acrylic acid) and phospholipid vesicles: Effect of pH, concentration, and molecular weight. J. Phys. Chem. B 2010, 114, 4828-4835. [CrossRef]

33. Adamo, G.; Grimaldi, N.; Campora, S.; Sabatino, M.A.; Dispenza, C.; Ghersi, G. Glutathione-sensitive nanogels for drug release. Chem. Eng. Trans. 2014, 38, 457-462. [CrossRef]

34. Dispenza, C.; Adamo, G.; Sabatino, M.A.; Grimaldi, N.; Bulone, D.; Bondì, M.L.; Rigogliuso, S.; Ghersi, G. Oligonucleotidesdecorated-poly(N-vinyl pyrrolidone) nanogels for gene delivery. J. Appl. Polym. Sci. 2014, 131, 1-8. [CrossRef]

35. Picone, P.; Ditta, L.A.; Sabatino, M.A.; Militello, V.; San Biagio, P.L.; Di Giacinto, M.L.; Cristaldi, L.; Nuzzo, D.; Dispenza, C.; Giacomazza, D.; et al. Ionizing radiation-engineered nanogels as insulin nanocarriers for the development of a new strategy for the treatment of Alzheimer's disease. Biomaterials 2016, 80, 179-194. [CrossRef] [PubMed] 
36. Picone, P.; Sabatino, M.A.; Ditta, L.A.; Amato, A.; San Biagio, P.L.; Mulè, F.; Giacomazza, D.; Dispenza, C.; Di Carlo, M. Nose-to-brain delivery of insulin enhanced by a nanogel carrier. J. Control. Release 2018, 270, 23-36. [CrossRef] [PubMed]

37. Farokhzad, O.C.; Jon, S.; Khademhosseini, A.; Tran, T.N.T.; LaVan, D.A.; Langer, R. Nanoparticle-aptamer bioconjugates: A new approach for targeting prostate cancer cells. Cancer Res. 2004, 64, 7668-7672. [CrossRef]

38. Mardhian, D.F.; Storm, G.; Bansal, R.; Prakash, J. Nano-targeted relaxin impairs fibrosis and tumor growth in pancreatic cancer and improves the efficacy of gemcitabine in vivo. J. Control. Release 2018, 290, 1-10. [CrossRef]

39. Kang, T.; Gao, X.; Hu, Q.; Jiang, D.; Feng, X.; Zhang, X.; Song, Q.; Yao, L.; Huang, M.; Jiang, X.; et al. INGR-modified PEG-PLGA nanoparticles that recognize tumor vasculature and penetrate gliomas. Biomaterials 2014, 35, 4319-4332. [CrossRef]

40. Chen, W.; Zou, Y.; Zhong, Z.; Haag, R. Cyclo(RGD)-decorated reduction-responsive nanogels mediate targeted chemotherapy of integrin overexpressing human glioblastoma in vivo. Small 2017, 13, 1-9. [CrossRef]

41. Cao, Z.; Yu, Q.; Xue, H.; Cheng, G.; Jiang, S. Nanoparticles for drug delivery prepared from amphiphilic PLGA zwitterionic block copolymers with sharp contrast in polarity between two blocks. Angew. Chemie Int. Ed. 2010, 49, 3771-3776. [CrossRef] [PubMed]

42. Ding, H.; Inoue, S.; Ljubimov, A.V.; Patil, R.; Portilla-Arias, J.; Hu, J.; Konda, B.; Wawrowsky, K.A.; Fujita, M.; Karabalin, N.; et al Inhibition of brain tumor growth by intravenous poly ( $\beta$-L-malic acid) nanobioconjugate with pH-dependent drug release. Proc. Natl. Acad. Sci. USA 2010, 107, 18143-18148. [CrossRef]

43. Wei, X.; Senanayake, T.H.; Warren, G.; Vinogradov, S.V. Hyaluronic acid-based nanogel-drug conjugates with enhanced anticancer activity designed for the targeting of CD44-positive and drug-resistant tumors. Bioconjug. Chem. 2013, 24, 658-668. [CrossRef] [PubMed]

44. Chen, J.; Ouyang, J.; Chen, Q.; Deng, C.; Meng, F.; Zhang, J.; Cheng, R.; Lan, Q.; Zhong, Z. EGFR and CD44 dual-targeted multifunctional hyaluronic acid nanogels boost protein delivery to ovarian and breast cancers in vitro and in vivo. ACS Appl. Mater. Interfaces 2017, 9, 24140-24147. [CrossRef]

45. Irby, D.; Du, C.; Li, F.; States, U. Lipid-drug conjugate for enhancing drug delivery. Mol. Pharmacol. 2018, 14, 1325-1338. [CrossRef] [PubMed]

46. Ling, L.; Du, Y.; Ismail, M.; He, R.; Hou, Y.; Fu, Z.; Zhang, Y.; Yao, C.; Li, X. Self-assembled liposomes of dual paclitaxelphospholipid prodrug for anticancer therapy. Int. J. Pharm. 2017, 526, 11-22. [CrossRef]

47. Hermanson, G.T. Chapter 14. Microparticles and nanoparticles. In Bioconjugate Techniques; Academic Press: Cambridge, MA, USA, 2013; pp. 549-587. ISBN 978-0-12-382239-0.

48. Hermanson, G.T. Chapter 3. The reactions of bioconjugation. In Bioconjugate Techniques; Academic Press: Cambridge, MA, USA, 2013; pp. 664-668. ISBN 978-0-12-382239-0.

49. Kunishima, M.; Kawachi, C.; Morita, J.; Terao, K.; Iwasaki, F.; Tani, S. 4-(4,6-Dimethoxy-1,3,5-triazin-2-yl)-4-methylmorpholinium chloride: An efficient condensing agent leading to the formation of amides and esters. Tetrahedron 1999, 55, 13159-13170. [CrossRef]

50. D'Este, M.; Eglin, D.; Alini, M. A systematic analysis of DMTMM vs EDC/NHS for ligation of amines to hyaluronan in water. Carbohydr. Polym. 2014, 108, 239-246. [CrossRef]

51. Kaminski, Z.J.; Kolesinska, B.; Kolesinska, J.; Sabatino, G.; Chelli, M.; Rovero, P.; Blaszczyk, M.; Glowka, M.L.; Papini, A.M. $\mathrm{N}$-triazinylammonium tetrafluoroborates. A new generation of efficient coupling reagents useful for peptide synthesis. J. Am. Chem. Soc. 2005, 127, 16912-16920. [CrossRef]

52. Kolesinska, B.; Rozniakowski, K.K.; Fraczyk, J.; Relich, I.; Maria Papini, A.; Kaminski, Z.J. The effect of counterion and tertiary amine on the efficiency of N-triazinylammonium sulfonates in solution and solid-phase peptide synthesis. Eur. J. Org. Chem. 2015, 2015, 401-408. [CrossRef]

53. Palao-Suay, R.; Martín-Saavedra, F.M.; Rosa Aguilar, M.; Escudero-Duch, C.; Martín-Saldaña, S.; Parra-Ruiz, F.J.; Rohner, N.A.; Thomas, S.N.; Vilaboa, N.; San Román, J. Photothermal and photodynamic activity of polymeric nanoparticles based on $\alpha$-tocopheryl succinate-RAFT block copolymers conjugated to IR-780. Acta Biomater. 2017, 57, 70-84. [CrossRef]

54. Chai, H.J.; Kiew, L.V.; Chin, Y.; Norazit, A.; Noor, S.M.; Lo, Y.L.; Looi, C.Y.; Lau, Y.S.; Lim, T.M.; Wong, W.F.; et al. Renal targeting potential of a polymeric drug carrier, poly-L-glutamic acid, in normal and diabetic rats. Int. J. Nanomed. 2017, 12, 577-591. [CrossRef]

55. Conejos-Sánchez, I.; Cardoso, I.; Oteo-Vives, M.; Romero-Sanz, E.; Paul, A.; Sauri, A.R.; Morcillo, M.A.; Saraiva, M.J.; Vicent, M.J. Polymer-doxycycline conjugates as fibril disrupters: An approach towards the treatment of a rare amyloidotic disease. J. Control. Release 2015, 198, 80-90. [CrossRef]

56. Carlson, R.H. Radioimmunotherapy-Chemotherapy Targets Advanced Pancreatic Cancer. Oncol. Times 2014, 36, 54-55. [CrossRef]

57. Definition of yttrium Y90 tacatuzumab tetraxetan. Available online: https://www.cancer.gov/publications/dictionaries/cancer$\mathrm{drug} /$ def/yttrium-y-90-tacatuzumab-tetraxetan (accessed on 28 July 2021).

58. Breeman, W.A.P.; de Blois, E.; Sze Chan, H.; Konijnenberg, M.; Kwekkeboom, D.J.; Krenning, E.P. 68Ga-labeled DOTA-Peptides and 68Ga-labeled Radiopharmaceuticals for Positron Emission Tomography: Current Status of Research, Clinical Applications, and Future Perspectives. Semin. Nucl. Med. 2011, 41, 314-321. [CrossRef] [PubMed]

59. Domingo, R.J.; Reilly, R.M. Pre-targeted radioimmunotherapy of human colon cancer xenografts in athymic mice using streptavidin-CC49 monoclonal antibody and 90Y-DOTA-biotin. Nucl. Med. Commun. 2000, 21, 89-96. [CrossRef] 
60. Knör, S.; Modlinger, A.; Poethko, T.; Schottelius, M.; Wester, H.-J.; Kessler, H. Synthesis of Novel 1,4,7,10-Tetraazacyclodecane1,4,7,10-Tetraacetic Acid (DOTA) Derivatives for Chemoselective Attachment to Unprotected Polyfunctionalized Compounds. Chem. Eur. J. 2007, 13, 6082-6090. [CrossRef]

61. Lee, D.S.; Im, H.J.; Lee, Y.S. Radionanomedicine: Widened perspectives of molecular theragnosis. Nanomed. Nanotechnol. Biol. Med. 2015, 11, 795-810. [CrossRef]

62. Kleynhans, J.; Grobler, A.F.; Ebenhan, T.; Sathekge, M.M.; Zeevaart, J.R. Radiopharmaceutical enhancement by drug delivery systems: A review. J. Control. Release 2018, 287, 177-193. [CrossRef]

63. McDevitt, M.R.; Sgouros, G.; Sofou, S. Targeted and nontargeted $\alpha$-particle therapies. Annu. Rev. Biomed. Eng. 2018, 20, 73-93. [CrossRef]

64. Buxton, G.V.; Greenstock, C.L.; Helman, W.P.; Ross, A.B. Critical Review of rate constants for reactions of hydrated electrons, hydrogen atoms and hydroxyl radicals $(\cdot \mathrm{OH} / \cdot \mathrm{O}-$ in Aqueous Solution. J. Phys. Chem. Ref. Data 1988, 17, 513-886. [CrossRef]

65. ASTM. Standard Practice for Use of the Alanine-EPR Dosimetry System; ASTM International: West Conshohocken, PA, USA, 2012; ISO/ASTM51607-13.

66. Kaiser, E.; Colescott, R.L.; Bossinger, C.D.; Cook, P.I. Color test for detection of free terminal amino groups in the solid-phase synthesis of peptides. Anal. Biochem. 1970, 34, 595-598. [CrossRef]

67. Ulanski, P.; Bothe, E.; Hildenbrand, K.; Rosiak, J.M.; von Sonntag, C. Hydroxyl radical-induced reactions of poly(acrylic acid); A pulse radiolysis, EPR and product study. Part I. Deoxygenated aqueous solutions. J. Chem. Soc. Perkin Trans. 2 1996, 1, 13-22. [CrossRef]

68. Arndt, K.-F.; Schmidt, T.; Reichelt, R. Thermo-sensitive poly(methyl vinyl ether) micro-gel formed by high energy radiation. Polymer (Guildf). 2001, 42, 6785-6791. [CrossRef]

69. Dispenza, C.; Grimaldi, N.; Sabatino, M.-A.; Todaro, S.; Bulone, D.; Giacomazza, D.; Przybytniak, G.; Alessi, S.; Spadaro, G. Studies of network organization and dynamics of e-beam crosslinked PVPs: From macro to nano. Radiat. Phys. Chem. 2012, 81, 1349-1353. [CrossRef]

70. Dispenza, C.; Sabatino, M.A.; Grimaldi, N.; Bulone, D.; Bondi, M.L.; Casaletto, M.P.; Rigogliuso, S.; Adamo, G.; Ghersi, G. Minimalism in radiation synthesis of biomedical functional nanogels. Biomacromolecules 2012, 13, 1805-1817. [CrossRef]

71. Ghaffarlou, M.; Sütekin, S.D.; Güven, O. Preparation of nanogels by radiation-induced cross-linking of interpolymer complexes of poly(acrylic acid) with poly(vinyl pyrrolidone) in aqueous medium. Radiat. Phys. Chem. 2018, 142, 130-136. [CrossRef]

72. An, J.-C.; Waver, A.; Kim, B.; Barkatt, A.; Poster, D.; Vreeland, W.N.; Silverman, J.; Al-Sheikhly, M. Radiation-induced synthesis of poly(vinylpyrrolidone) nanogels. Polymer 2011, 52, 5746-5755. [CrossRef]

73. von Sonntag, C. The Chemical Basis of Radiation Biology; Taylor and Francis: London, UK, 1987.

74. Ulanski, P.; Bothe, E.; Hildenbrand, K.; Rosiak, J.M.; von Sonntag, C. Hydroxyl-radical-induced reactions of poly(acrylic acid); A pulse radiolysis, EPR and product study. Part II. Oxygenated aqueous solutions. J. Chem. Soc. Perkin Trans. 2 1996, 1, 23-28. [CrossRef]

75. Molyneux, P. Water-soluble synthetic polymers. In Properties and Applications; CRC Press. Inc.: Boca Raton, FL, USA, 1987.

76. Oosawa, F. Polyelectrolytes; Marcel Dekker: New York, NY, USA, 1971.

77. Burchard, W. Solution properties of branched macromolecules. Adv. Polym. Sci. 1999, 143, 114-194. [CrossRef]

78. Moharram, M.A.; Balloomal, L.S.; El-Gendy, H.M. Infrared study of the complexation of poly(acrylic acid) with poly(acrylamide). J. Appl. Polym. Sci. 1996, 59, 987-990. [CrossRef]

79. Dong, J.; Ozaki, Y.; Nakashima, K. Infrared, Raman, and near-infrared spectroscopic evidence for the coexistence of various hydrogen-bond forms in poly(acrylic acid). Macromolecules 1997, 30, 1111-1117. [CrossRef]

80. Mojumdar, S.C.; Raki, L. Preparation, thermal, spectral and microscopic studies of calcium silicate hydrate-poly (acrylic acid) nanocomposite materials. J. Therm. Anal. Calorim. 2006, 85, 99-105. [CrossRef]

81. Refat, M.S.; Sadeek, S.A.; Khater, H.M. Electronic, infrared, and 1HNMR spectral studies of the novel charge-transfer complexes of o-tolidine and p-toluidine with alternation $\pi$-acceptors (3,5-dinitro benzoic acid and 2,6-dichloroquinone-4-chloroimide) in $\mathrm{CHCl} 3$ solvent. Spectrochim. Acta Part A Mol. Biomol. Spectrosc. 2006, 64, 778-788. [CrossRef]

82. Singh, N.; Khan, I.M.; Ahmad, A. Spectrophotometric and spectroscopic studies of charge transfer complexes of p-toluidine as an electron donor with picric acid as an electron acceptor in different solvents. Spectrochim. Acta Part A Mol. Biomol. Spectrosc. 2010, 75, 1347-1353. [CrossRef]

83. Zoromba, M.S. Novel and economic acid-base indicator based on (p-toluidine) oligomer: Synthesis; characterization and solvatochromism applications. Spectrochim. Acta Part A Mol. Biomol. Spectrosc. 2017, 187, 61-67. [CrossRef]

84. Thomas, O.; Brogat, M. Chapter 12-UV Spectra Library. In UV-Visible Spectrophotometry of Water and Wastewater; Thomas, O., Burgess, C., Eds.; Elsevier: Amsterdam, The Netherlands, 2017; pp. 379-517. ISBN 978-0-444-63897-7.

85. Vandenbelt, J.M.; Henrich, C.; Vanden Berg, S.G. Comparison of pKa values determined by electrometric titration and ultraviolet absorption methods. Anal. Chem. 1954, 26, 726-727. [CrossRef]

86. Liu, A.; Honma, I.; Ichihara, M.; Zhou, H. Poly(acrylic acid)-wrapped multi-walled carbon nanotubes composite solubilization in water: Definitive spectroscopic properties. Nanotechnology 2006, 17, 2845-2849. [CrossRef]

87. Kavitha, T.; Kang, I.-K.; Park, S.-Y. Poly (acrylic acid)-grafted graphene oxide as an intracellular protein carrier. Langmuir 2014, 30, 402-409. [CrossRef] 
88. Filippov, A.; Munavirov, B.; Sparrman, T.; Ishmuhametova, V.; Rudakova, M.; Shriram, P.; Tavelin, S. Interaction of a poly(acrylic acid) oligomer with dimyristoylphosphatidylcholine bilayers. Langmuir 2011, 27, 3754-3761. [CrossRef] [PubMed]

89. Abraham, R.J.; Mobli, M. Modelling 1H NMR Spectra of Organic Compounds: Theory, Applications and NMR Prediction Software; Wiley: Chichester, UK, 2008.

90. Malde, A.K.; Zuo, L.; Breeze, M.; Stroet, M.; Poger, D.; Nair, P.C.; Oostenbrink, C.; Mark, A.E. An automated force field topology builder (ATB) and repository: Version 1.0. J. Chem. Theory Comput. 2011, 7, 4026-4037. [CrossRef] [PubMed]

91. Koziara, K.B.; Stroet, M.; Malde, A.K.; Mark, A.E. Testing and validation of the automated topology builder (ATB) version 2.0: Prediction of hydration free enthalpies. J. Comput. Aided Mol. Des. 2014, 28, 221-233. [CrossRef] [PubMed]

92. Canzar, S.; El-Kebir, M.; Pool, R.; Elbassioni, K.; Malde, A.K.; Mark, A.E.; Geerke, D.P.; Stougie, L.; Klau, G.W. Charge Group Partitioning in Biomolecular Simulation. J. Comput. Biol. 2013, 20, 188-198. [CrossRef]

93. Mendoza-Nava, H.; Ferro-Flores, G.; Ramírez, F.D.M.; Ocampo-García, B.; Santos-Cuevas, C.; Aranda-Lara, L.; Azorín-Vega, E.; Morales-Avila, E.; Isaac-Olivé, K. 177Lu-dendrimer conjugated to folate and bombesin with gold nanoparticles in the dendritic cavity: A potential theranostic radiopharmaceutical. J. Nanomater. 2016, 2016, 1039258. [CrossRef]

94. Aranda-Lara, L.; Ferro-Flores, G.; Azorín-Vega, E.; de Maria Ramírez, F.; Jiménez-Mancilla, N.; Ocampo-García, B.; Santos-Cuevas, C.; Isaac-Olivé, K. Synthesis and evaluation of Lys1( $\alpha, \gamma$-Folate)Lys3(177Lu-DOTA)-Bombesin(1-14) as a potential theranostic radiopharmaceutical for breast cancer. Appl. Radiat. Isot. 2016, 107, 214-219. [CrossRef]

95. Hajiramezanali, M.; Atyabi, F.; Mosayebnia, M.; Akhlaghi, M.; Geramifar, P.; Jalilian, A.R.; Mazidi, S.M.; Yousefnia, H.; Shahhosseini, S.; Beiki, D. (68)Ga-radiolabeled bombesin-conjugated to trimethyl chitosan-coated superparamagnetic nanoparticles for molecular imaging: Preparation, characterization and biological evaluation. Int. J. Nanomed. 2019, 14, 2591-2605. [CrossRef] [PubMed]

96. Hixon, J.; Reshetnyak, Y.K. Algorithm for the analysis of tryptophan fluorescence spectra and their correlation with protein structural parameters. Algorithms 2009, 2, 1155-1176. [CrossRef]

97. Accardo, A.; Mannucci, S.; Nicolato, E.; Vurro, F.; Diaferia, C.; Bontempi, P.; Marzola, P.; Morelli, G. Easy formulation of liposomal doxorubicin modified with a bombesin peptide analogue for selective targeting of GRP receptors overexpressed by cancer cells. Drug Deliv. Transl. Res. 2019, 9, 215-226. [CrossRef] [PubMed]

98. Carver, J.A. The conformation of bombesin in solution as determined by two-dimensional 1H-NMR techniques. Eur. J. Biochem. 1987, 168, 193-199. [CrossRef]

99. Valliant, J.F.; Riddoch, R.W.; Hughes, D.W.; Roe, D.G.; Fauconnier, T.K.; Thornback, J.R. The solid phase synthesis and NMR spectroscopy of a 99Tc chelate-bombesin derived peptide conjugate. Inorg. Chim. Acta 2001, 325, 155-163. [CrossRef]

100. Aime, S.; Botta, M.; Cravotto, G.; Frullano, L.; Giovenzana, G.B.; Crich, S.G.; Palmisano, G.; Sisti, M. Gadolinium(III) complexes of dota-derived N-sulfonylacetamides (H 4(dota-NHSO2R) = 10-\{2-[(R)sulfonylamino]-2-oxoethyl $\}-1,4,7,10$-tetraazacyclododecane1,4,7-triacetic acid): A new class of relaxation agents for magnetic resonance imaging applications. Helv. Chim. Acta 2005, 88, 588-603. [CrossRef] 